\title{
The inter-comparison of major satellite aerosol retrieval algorithms using simulated intensity and polarization characteristics of reflected light
}

\author{
A. A. Kokhanovsky ${ }^{1}$, J. L. Deuzé2 ${ }^{2}$, D. J. Diner ${ }^{3}$, O. Dubovik ${ }^{2}$, F. Ducos ${ }^{2}$, C. Emde ${ }^{4}$, M. J. Garay ${ }^{5}$, R. G. Grainger ${ }^{6}$, \\ A. Heckel ${ }^{7}$, M. Herman ${ }^{2}$, I. L. Katsev ${ }^{8}$, J. Keller ${ }^{9}$, R. Levy ${ }^{10}$, P. R. J. North ${ }^{7}$, A. S. Prikhach ${ }^{8}$, V. V. Rozanov ${ }^{1}$, \\ A. M. Sayer ${ }^{6}$, Y. Ota ${ }^{11}$, D. Tanré2 , G. E. Thomas ${ }^{6}$, and E. P. Zege ${ }^{8}$ \\ ${ }^{1}$ Institute of Environmental Physics, University of Bremen, O. Hahn Allee 1, 28334 Bremen, Germany \\ ${ }^{2}$ Lab. d'Optique Atmosphérique, UMR CNRS 8518, Bat. P5, Université Lille 1, 59655 - Villeneuve d'Ascq cedex, France \\ ${ }^{3}$ Jet Propulsion Lab., California Institute of Technology, MS 169-237, 4800 Oak Grove Drive, Pasadena, CA 91109, USA \\ ${ }^{4}$ Deutsches Zentrum für Luft- und Raumfahrt (DLR), Münchner Straße 20, 82234 Weßling, Germany \\ ${ }^{5}$ Raytheon Intelligence and Information Systems, 299 N. Euclid Ave., Suite 500, Pasadena, CA 91101, USA \\ ${ }^{6}$ Atmospheric, Oceanic and Planetary Physics, Department of Physics, University of Oxford, Clarendon Laboratory, Parks \\ Road, Oxford, OX1 3PU, UK \\ ${ }^{7}$ School of the Environment and Society, Swansea University, Singleton Park, Swansea, SA2 8PP, UK \\ ${ }^{8}$ Institute of Physics, National Academy of Sciences of Belarus, Pr. Nezavisimosti 68, 220072, Minsk, Belarus \\ ${ }^{9}$ Paul Scherrer Institute, Laboratory of Atmospheric Chemistry (LAC), 5232 Villigen PSI, Switzerland \\ ${ }^{10}$ SSAI, 10210 Greenbelt Road, Suite 600, Lanham, MD 20706, USA \\ ${ }^{11}$ National Institute for Environmental Studies, 16-2 Onogawa, Tsukuba, Japan
}

Received: 23 November 2009 - Published in Atmos. Meas. Tech. Discuss.: 22 December 2009

Revised: 13 March 2010 - Accepted: 28 April 2010 - Published: 15 July 2010

\begin{abstract}
Remote sensing of aerosol from space is a challenging and typically underdetermined retrieval task, requiring many assumptions to be made with respect to the aerosol and surface models. Therefore, the quality of a priori information plays a central role in any retrieval process (apart from the cloud screening procedure and the forward radiative transfer model, which to be most accurate should include the treatment of light polarization and molecular-aerosol coupling). In this paper the performance of various algorithms with respect to the of spectral aerosol optical thickness determination from optical spaceborne measurements is studied. The algorithms are based on various types of measurements (spectral, angular, polarization, or some combination of these). It is confirmed that multiangular spectropolarimetric measurements provide more powerful constraints compared to spectral intensity measurements alone, particularly those acquired at a single view angle and which rely on a priori assumptions regarding the particle phase function in the retrieval process.
\end{abstract}

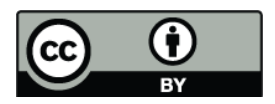

Correspondence to: A. A. Kokhanovsky (alexk@iup.physik.uni-bremen.de)

\section{Introduction}

The determination of spectral aerosol optical thickness (AOT) from satellites is of importance for a number of problems including global climate change studies, radiative forcing, air quality, visibility, and influence of aerosols on trace gas and cloud retrieval techniques based on spaceborne observations. The advances and problems related to aerosol remote sensing from space have recently been reviewed (Kokhanovsky and de Leeuw, 2009; Lee et al., 2009). In particular, it was found that different algorithms/instruments produce somewhat different results for AOT absolute values and spatial distributions even if the same location at the same time is observed (Kahn et al., 2007; Kokhanovsky et al., 2007; Liu and Mishchenko, 2008; Mishchenko et al., 2009; Kahn et al., 2009). Li et al. (2009) list the following possible reasons for the discrepancy: (1) cloud masking; (2) instrument calibration; (3) treatment of the underlying surface; (4) assumptions on the aerosol model.

The task of this paper is to compare several major AOT retrieval algorithms using synthetic top-of-atmosphere (TOA) solar backscattered light characteristics over a black surface. Then reasons 1-3 given above are eliminated and the

Published by Copernicus Publications on behalf of the European Geosciences Union. 


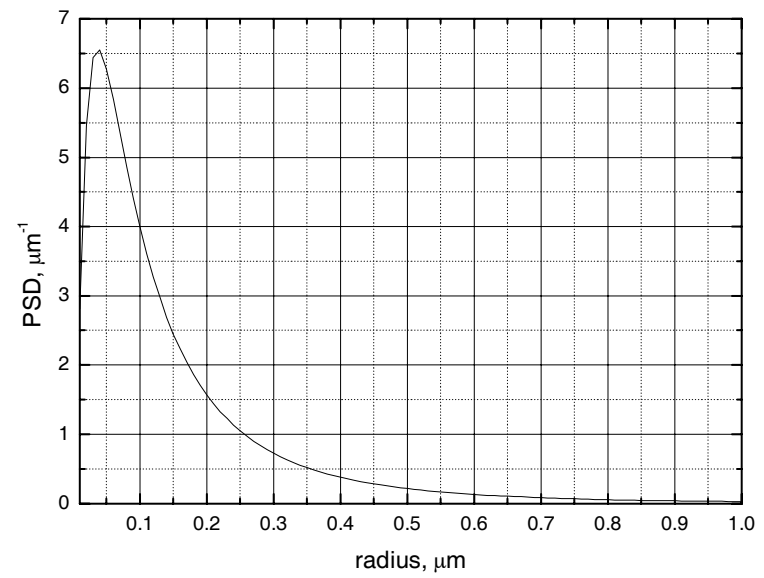

Fig. 1. Particle size distribution.

correctly working algorithms ideally should produce similar results when applied to the synthetic data. The only remaining difference is due to the assumptions about the aerosol model. Clearly, if an incorrect assumption is made, then retrievals will be biased. The best algorithm must retrieve not only AOT but the aerosol model (e.g., the aerosol phase function) from the measurements themselves. This is not always possible and depends on the type of instrument employed.

The paper is structured as follows. In the next section we introduce the oceanic aerosol model used for the creation of the synthetic dataset. Section 3 is aimed at the description of the vector radiative transfer model applied for the calculation of the Stokes vector at the top of atmosphere for the case of black underlying surface and the absence of gaseous absorption. Multiple light scattering by aerosol particles and molecules are fully taken into account. The selected aerosol retrievals algorithms for several satellite instruments currently in operation are briefly outlined in Sect. 4 . The final Sect. 5 is devoted to the description of the results obtained in this work.

\section{Aerosol model}

For this study it is assumed that the aerosol is composed of oceanic-type particles with refractive index equal to $1.38-10^{-8} i$ at wavelengths $\lambda=400-900 \mathrm{~nm}$. At the longer wavelengths of $1243,1632,1670$, and $2119 \mathrm{~nm}$ calculations have also been done assuming that the real part of the refractive index is 1.35 and the imaginary part is 0.0003 at $1243 \mathrm{~nm}, 0.001$ for the wavelengths close to $1600 \mathrm{~nm}$, and 0.003 at $2119 \mathrm{~nm}$. These values of the refractive index were recommended by the World Climate Programme (WCP-112) for the case of oceanic aerosol. We used the following lognormal particle size distribution (PSD):

$f(a)=\frac{1}{\sqrt{2 \pi} s a} \exp \left[-\frac{\ln ^{2}\left(a / a_{0}\right)}{2 s^{2}}\right]$,

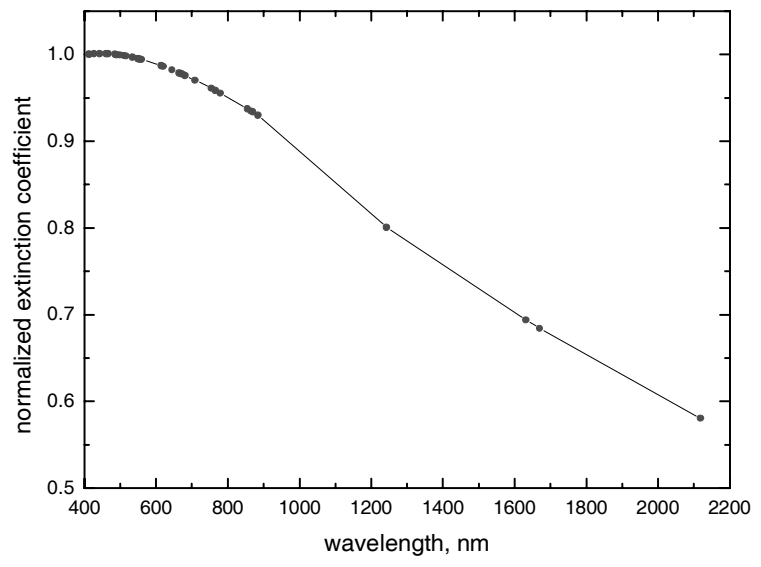

Fig. 2. Spectral normalized extinction coefficient $\kappa(\lambda)=K_{\text {ext }}(\lambda) / K_{\text {ext }}\left(\lambda_{0}\right)$, where $\lambda_{0}=412 \mathrm{~nm}$.

where $a$ is the radius of aerosol particles, and we set $s=1$ and $a_{0}=100 \mathrm{~nm}$. The distribution is shown in Fig. 1. This distribution is not very representative as far as real multi-modal atmospheric aerosol size distributions are of concern. However, it is known that the optical parameters of aerosol are mostly influenced by the effective size of particles (and to some extent by the effective variances) and not by the exact form of the PSD.

The aerosol optical properties (spectral extinction $K_{\text {ext }}$, spectral single scattering albedo $\omega_{0}$ and also spectral phase matrix $\hat{\mathbf{Z}}(\theta), \theta$ is the scattering angle) of the spherical polydispersion described by the PSD (1) have been calculated using Mie theory for each wavelength assuming the minimum radius $a_{\min }=0.05 \mu \mathrm{m}$ and the maximum radius $a_{\max }=20 \mu \mathrm{m}$ (Kokhanovsky, 2008). The effective radius $a_{\text {ef }}$ and the effective variance $v_{\text {ef }}$ are $1.2 \mu \mathrm{m}$ and 1.5, respectively, for this (truncated) distribution. The effective radius is defined as the ratio of the third-to-second moment of the truncated PSD (1) $\left(a_{\mathrm{ef}}=\left\langle a^{3}\right\rangle /\left\langle a^{2}\right\rangle\right)$ and $v_{\mathrm{ef}}=\left\langle a^{4}\right\rangle\left\langle a^{2}\right\rangle /\left\langle a^{3}\right\rangle^{2}-1$. Here brackets \langle\rangle mean averaging with respect to the truncated PSD (1).

The normalized extinction coefficient is shown in Fig. 2 (see also Appendix). The single scattering albedo is equal to 1.0 for all channels except channels at $\lambda \geq 1243 \mathrm{~nm}$, where we used the following values obtained from Mie theory for the refractive indices given above: $\omega_{0}(1243 \mathrm{~nm})=0.9959$, $\omega_{0}(1670 \mathrm{~nm})=0.9886, \omega_{0}(2119 \mathrm{~nm})=0.97$. The phase function and the normalized phase matrix elements $P_{i j}=Z_{i j} / Z_{11}$ at $550 \mathrm{~nm}$ are shown in Fig. 3. The phase function is also given in Appendix. The asymmetry parameter is almost spectrally neutral and equal to $0.77-0.78$ depending on the wavelength.

Summing up, it follows that the selected aerosol model is characterized by weak absorption in the shortwave infrared. Particles are also quite large so the spectral extinction coefficient does not vary much in the visible (see Fig. 2). However, it drops significantly (almost by half) at $2119 \mathrm{~nm}$ as 

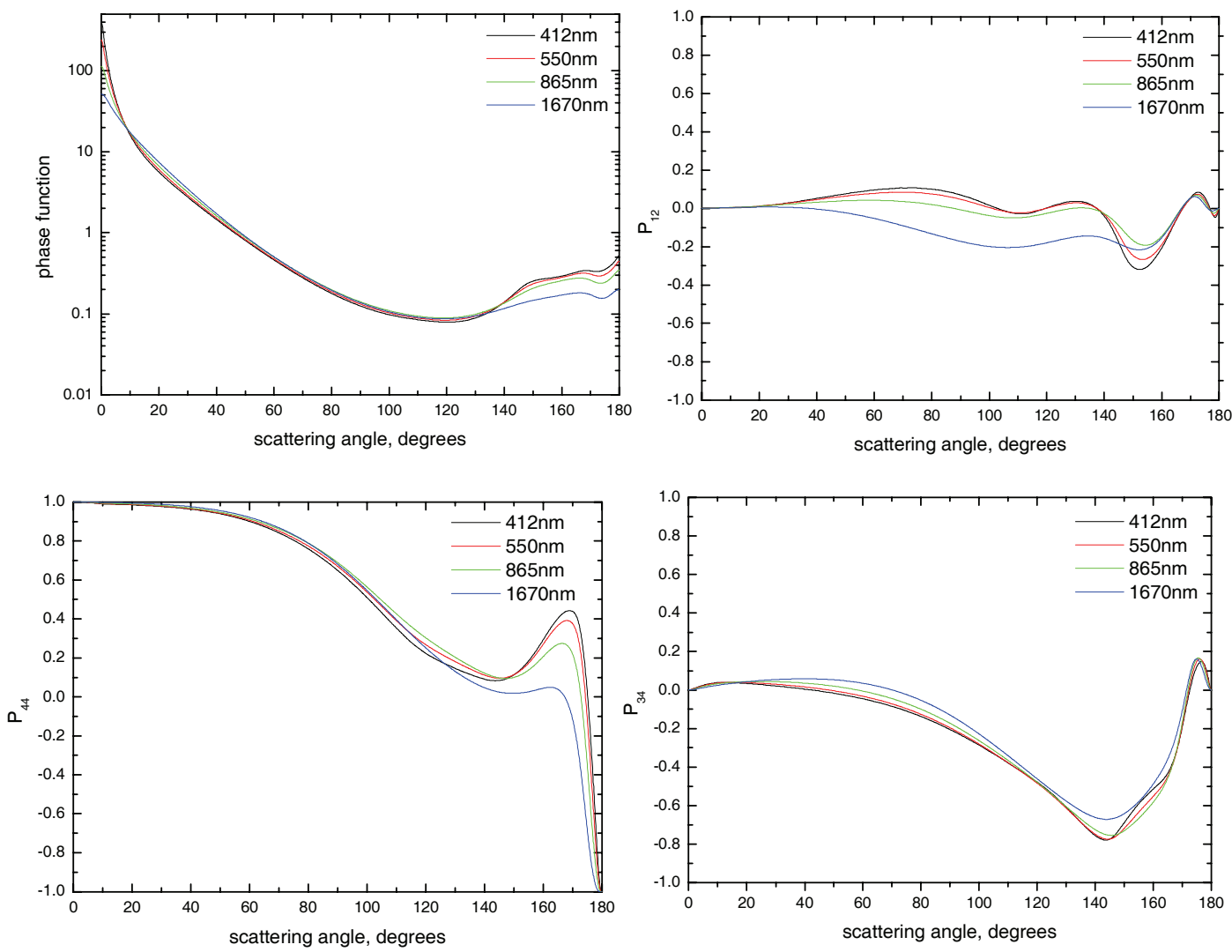

Fig. 3. Phase function and normalized phase matrix elements.

compared to the value at $412 \mathrm{~nm}$. The phase function is also only weakly dependent on the wavelength in the visible (see Fig. 3). The degree of polarization ( $p=-P_{12}$, see Fig. 3 ) is smaller than $30 \%$. Therefore, particles only weakly polarize incident solar light. The element $P_{34}$ takes quite large values in the region $140-160^{\circ}$, which indicates the large size of particles and their spherical shape. Generally (with the exception of $P_{44}$ around $170^{\circ}$ ) the phase matrix elements do not have a pronounced spectral dependence, which is characteristic of large aerosol particles.

\section{Radiative transfer model used to create the synthetic dataset for retrievals}

Radiative transfer calculations of the Stokes vector $S(I, Q, U, V)$ of reflected solar light were performed using the comprehensive software package SCIATRAN developed at University of Bremen (UB) (Rozanov et al., 2005; Rozanov and Kokhanovsky, 2006). SCIATRAN employs the discrete ordinates method (DOM) of solving the vector radiative transfer equation. The method is based on the following steps:
- the phase matrix is expanded in a series using generalized spherical harmonic functions.

- the Stokes vector is expanded in a Fourier series with respect to the relative azimuth.

- the integration with respect to azimuth is performed analytically.

- integrations over zenith angle use Gaussian quadrature.

- the system of differential equations derived in such a way is solved analytically (separately for cases $\omega_{0}=1$ and $\left.\omega_{0} \neq 1\right)$.

- the arbitrary constants in the analytical solution of the system of differential equations are found numerically using boundary conditions and solving the corresponding system of linear algebraic equations.

- the approach given above is valid for homogeneous atmospheric layers. Therefore, for a realistic vertically inhomogeneous atmosphere, the atmosphere is divided into a number of thin homogeneous layers. The technique is followed for each sub-layer with the requirement of continuity in the solution at the boundaries between layers. 

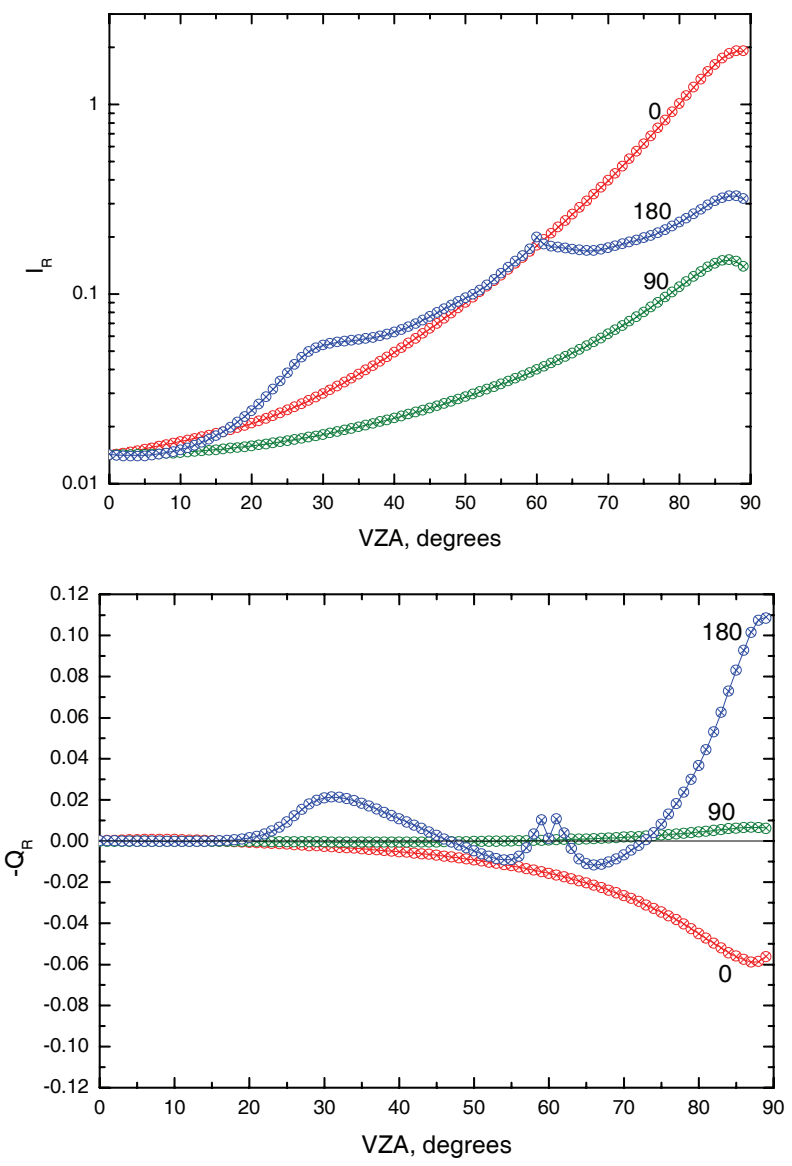

Fig. 4a. The comparison of the reflection function (upper panel) and the second Stokes parameter (lower panel) for the case of oceanic aerosol with the optical thickness 0.3262 (at $412 \mathrm{~nm}$ ) obtained using three independent radiative transfer codes. The calculations have been performed at the solar zenith angle $\vartheta_{0}=60^{\circ}$ and the relative azimuths $\varphi=0^{\circ}, 90^{\circ}, 180^{\circ}$ as the function of the viewing zenith angle (SCIATRAN - line, circles - Pstar, crosses - MYSTIC).

In the simulations, it was assumed that gaseous absorption is negligible and the underlying surface is black. This was done to simplify the solution of the inverse problem. The accuracy of SCIATRAN was studied through comparisons with other radiative transfer codes and it was found that differences are $<1 \%$ for all cases considered (Kokhanovsky et al., 2010). An example of comparisons of SCIATRAN with the Monte-Carlo (MC) radiative transfer model MYSTIC (Emde et al., 2010; Mayer, 2009) developed at the German Space Agency (DLR) and the code Pstar based on the discrete ordinate method developed by Ota et al. (2010) at National Institute for Environmental Studies (NIES, Japan) is given in Fig. 4 as the function of the viewing zenith angle (VZA) at $\lambda=412 \mathrm{~nm}$ for the case of a homogeneous plane-parallel layer with the aerosol size distribution given by Eq. (1) and $a_{0}=0.3 \mu \mathrm{m}, s=0.92, a_{\max }=30 \mu \mathrm{m}, m=1.385$. The elements of the normalized Stokes vector were calculated using the
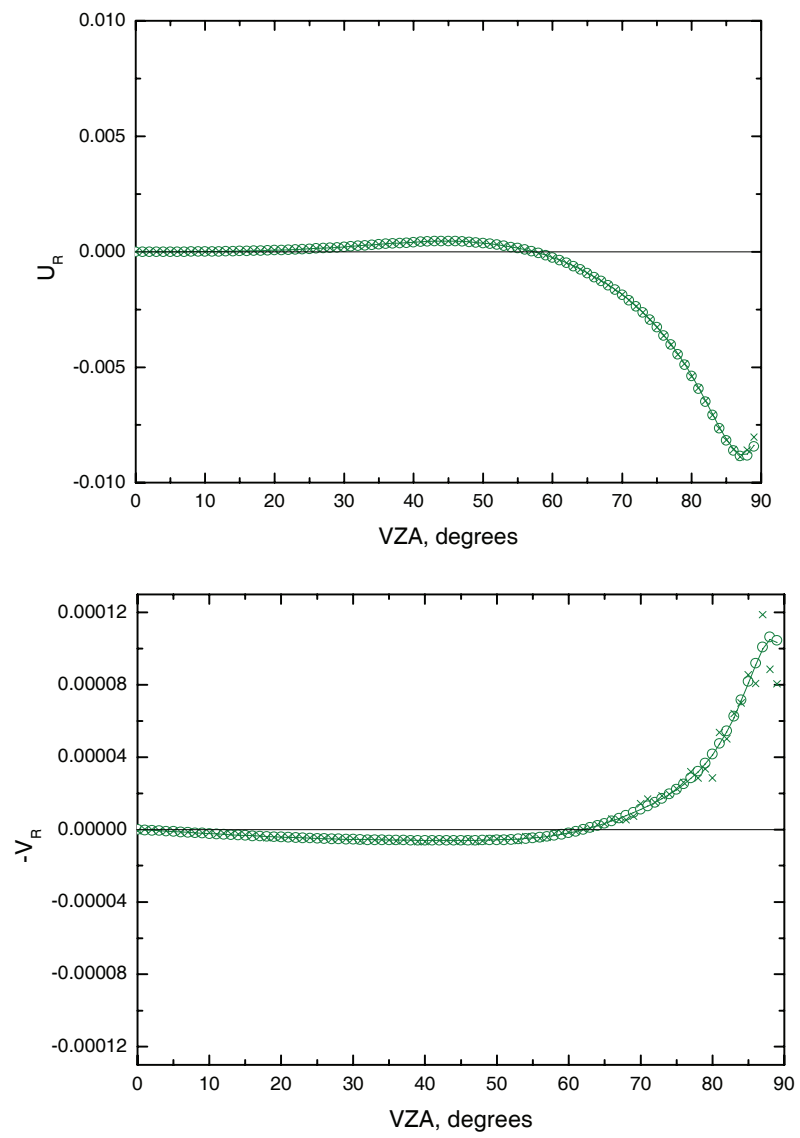

Fig. 4b. The same as in Fig. 4a except for the third and forth Stokes vector elements at $\varphi=90^{\circ}$.

following equations:

$I_{\mathrm{R}}=\pi I / \mu_{0} F_{0}, Q_{\mathrm{R}}=\pi Q / \mu_{0} F_{0}$,

$U_{\mathrm{R}}=\pi U / \mu_{0} F_{0}, V_{\mathrm{R}}=\pi V / \mu_{0} F_{0}$.

Here $\mu_{0}$ is the cosine of the solar zenith angle (SZA) $\vartheta_{0}$ and $F_{0}$ is the solar irradiance at the TOA. For these code comparisons the albedo of the underlying surface was zero and there were no molecular scattering or absorption effects. Similar comparisons have been performed at other illumination/observation conditions and also for other aerosol and cloudy media (Kokhanovsky et al., 2010). They confirmed the high accuracy of the code used for the simulations performed in this work.

The first element of the normalized Stokes vector of the reflected light (see Eq. ??) calculated using SCIATRAN for the aerosol model described in the previous section is presented in Fig. 5 at the wavelength $412 \mathrm{~nm}$ as the function of the aerosol optical thickness.

A homogeneous plane-parallel aerosol layer located in the height range $0-2 \mathrm{~km}$ above ground was assumed in calculations. Molecular scattering was fully taken into account. The Rayleigh depolarization factor was assumed to be equal 


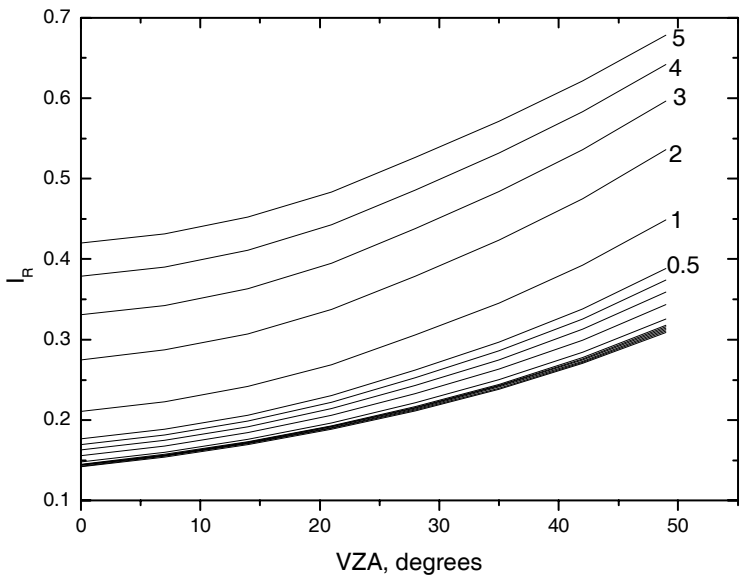

Fig. 5. The dependence of the first normalized Stokes vector component at $\lambda=412 \mathrm{~nm}$, the solar zenith angle $60^{\circ}$, and the relative azimuth $180^{\circ}$ on the viewing zenith angle for the aerosol model described in Sect. 2. The aerosol is contained in the plane-parallel layer positioned in the region $0-2 \mathrm{~km}$ above the black underlying surface. The molecular scattering is taken into account. The gaseous absorption is neglected. The aerosol optical thickness at $412 \mathrm{~nm}$ is assumed to be equal $0,0.01(0.01) 0.05,0.1(0.1) 0.5,1,2$, $3,4,5$. The lower lines correspond to the smaller values of AOT.

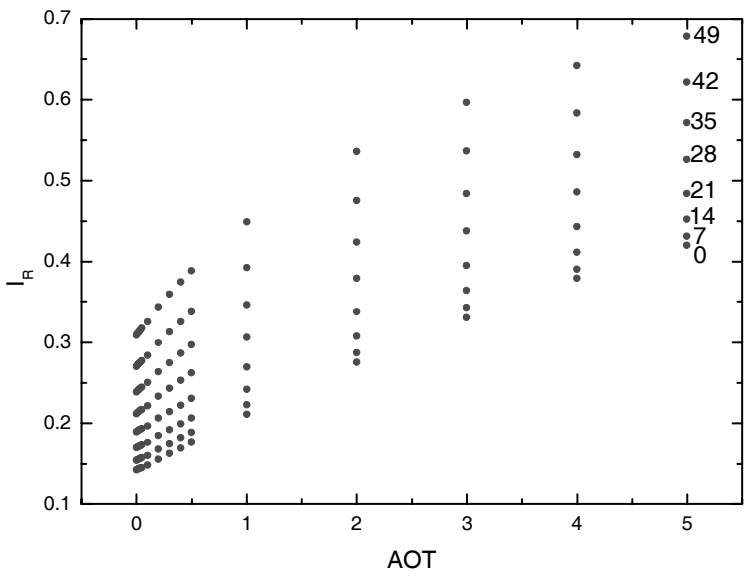

Fig. 6. The same as in Fig. 5 except as the function of AOT $(412 \mathrm{~nm})$ for the $\mathrm{VZA}=0^{\circ}\left(7^{\circ}\right) 49^{\circ}$ and the discrete points, where forward calculations were performed. The upper points correspond to $\mathrm{VZA}=49^{\circ}$ and the lower system of points corresponds to $\mathrm{VZA}=0^{\circ}$.

to 0.0295 and independent of wavelength. The vertical profile of the spectral molecular scattering coefficient was taken from the SCIATRAN database (for the latitude $45^{\circ} \mathrm{N}$ ).

The data shown in Fig. 5 are re-plotted in Fig. 6 as a function of AOT for several values of the viewing zenith angle. The non-zero values of reflectance at $\mathrm{AOT}=0.0$ are due to the contribution of molecular scattering, which is quite significant in the blue spectral region. It follows that as one might expect the reflectance $\left(R \equiv I_{\mathrm{R}}\right)$ increases both with AOT $\tau$ and viewing zenith angle (VZA).

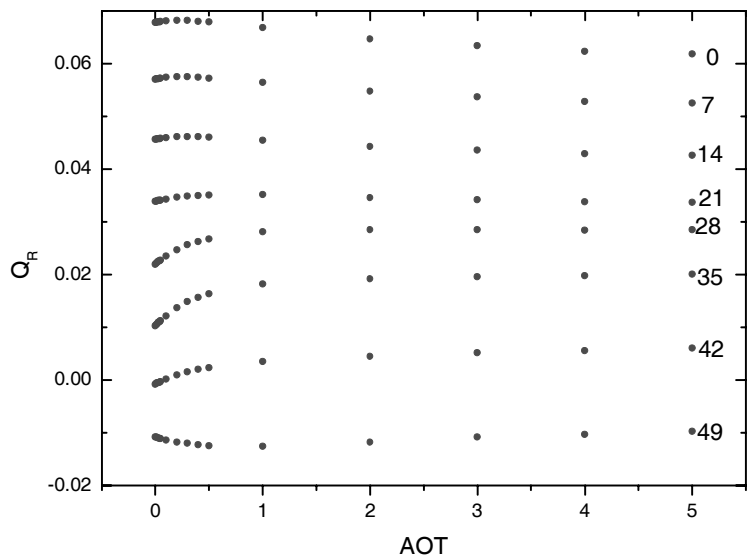

Fig. 7. The same as in Fig. 6 except for $Q_{\mathrm{R}}$.

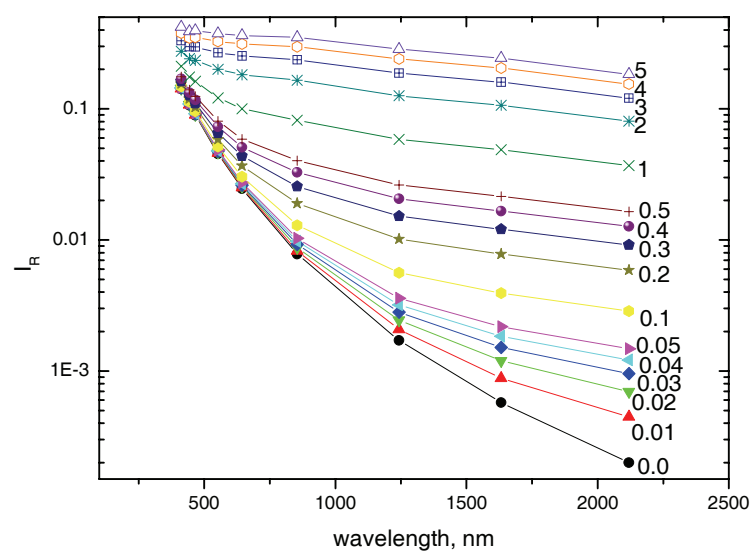

Fig. 8. Spectral reflectance presented for various values of AOT $(412 \mathrm{~nm})$ at the nadir observation and the SZA equal to $60^{\circ}$.

The value of the second Stokes parameter decreases with the VZA for angles $<40^{\circ}$ and then it changes sign (see Fig. 7). The dependence of $Q_{\mathrm{R}}$ on the AOT is not significant for $A O T \geq 1$, where the results are very close to those for a semi-infinite medium. Then they are determined exclusively by the aerosol model and not by the optical thickness. The behavior $Q_{\mathrm{R}}(\tau)$ depends on the value of VZA. In most of cases $Q_{\mathrm{R}}$ increases with $\tau$ reaching its asymptotic value $Q_{\mathrm{R}}(\infty)$. However, this is not the case for large VZAs (e.g., $49^{\circ}$, see Fig. 7).

The spectral dependence of reflectance is given in Fig. 8 for various values of AOT. It follows that for larger AOTs, the spectral dependence is less pronounced. The spectral dependence is quite strong for low aerosol loads, and especially for the pure molecular atmosphere (the line with $\mathrm{AOT}=0.0$ in Fig. 8).

Clearly, for the most accurate and complete inverse problem solution, one must analyze the full Stokes vector and its dependence on the wavelength and viewing/illumination geometry. The circular polarization can reasonably be ignored under typical atmospheric conditions $(V=0)$. The 
Table 1. The capabilities of modern satellite instruments for aerosol remote sensing.

\begin{tabular}{|c|c|c|c|}
\hline Instrument & $\begin{array}{l}\text { Spectral channels used for } \\
\text { aerosol retrievals in this work, nm }\end{array}$ & Viewing geometry & Polarization measurements \\
\hline MODIS & $\begin{array}{l}466,553,644,855 \\
1243,1632,2119\end{array}$ & 1 observation angle & No \\
\hline MERIS & $\begin{array}{l}412,443,490,510,560,620 \\
665,681,709,754,779,865,885\end{array}$ & 1 observation angle & No \\
\hline AATSR & $555,659,865,1610$ & $\begin{array}{l}2 \text { observation angles: } \\
0^{\circ}-22^{\circ}, 55^{\circ}\end{array}$ & No \\
\hline MISR & $446,558,672,866$ & $\begin{array}{l}9 \text { observation angles: } \\
0^{\circ}, \pm 26.1^{\circ}, \pm 46.1^{\circ}, \pm 60^{\circ}, \pm 70.5^{\circ} \\
\text { (“+”" means forward and } \\
\text { "_-“ means backward) }\end{array}$ & No \\
\hline POLDER & $\begin{array}{l}443,490,565,670 \\
865,1020\end{array}$ & $\begin{array}{l}16 \text { observation angles } \\
\text { (in the range }\left[-55^{\circ}, 55^{\circ}\right] \text { ) }\end{array}$ & $\begin{array}{l}\text { Yes } Q, U \text { at } 490, \\
670,865 \mathrm{~nm}\end{array}$ \\
\hline GLORY & $\begin{array}{l}412,443,555,670,865 \\
910,1378,1590,2250\end{array}$ & $\begin{array}{l}180 \text { observation angles } \\
\text { (in the range }\left[-62^{\circ}, 50^{\circ}\right] \text { ) }\end{array}$ & $\begin{array}{l}\text { Yes } Q, U \text { at } 9 \text { bands } \\
\text { given in the first column }\end{array}$ \\
\hline
\end{tabular}

most important information comes from the first two components $(I, Q)$. Practical instruments and achievable geometries from Earth orbit results in a subset of observable parameters and locations in the phase space with coordinates $\left(\vartheta_{0}, \vartheta, \varphi, \lambda, i\right)$, where $i$ numbers the Stokes components. Combined spectroradiometric and spectropolarimetric observations of the same atmospheric column using different viewing zenith angles contain the greatest information content. The capabilities of some modern satellite instruments are given in Table 1 . In the next section, we briefly describe the selected algorithms developed to date for the instruments mentioned in Table 1.

\section{Aerosol retrieval algorithms}

\subsection{MODIS “dark-target” retrievals over land and ocean}

The Moderate resolution Imaging Spectrometer (MODIS; Salomonson et al., 1989) has been flying aboard Terra since December 1999 and aboard Aqua since May 2002. MODIS observes spectral radiance in 36 wavelength bands, ranging from 0.412 to $41.2 \mu \mathrm{m}$, with spatial resolutions of $250-1 \mathrm{~km}$, depending on channel. From polar orbit $(700 \mathrm{~km})$, MODIS views a $2300 \mathrm{~km}$ wide swath, providing near daily coverage of Earth's surface and atmosphere. This combination of swath, resolution, and spectral information is great enough to enable statistical retrieval of aerosol. By aggregating the finer resolution pixels, MODIS can separate cloudy and clear sky pixels so that there is enough signal to consistently and accurately retrieve aerosol properties on $10 \mathrm{~km} \times 10 \mathrm{~km}$ resolution (Levy, 2009).
The aerosol algorithm has been formulated to derive global aerosol properties from window-band observations in the visible (VIS) near-infrared (NIR) and shortwave-infrared (SWIR). In fact the algorithm is composed of three separate algorithms to derive AOT over different types of surfaces. The dark-target portion refers to the separate retrievals over "dark" (e.g., vegetated) land (Kaufman et al., 1997) and "dark" (non-glint) deep ocean areas (Tanré et al., 1997). Recently, a bright-target algorithm has been developed based on the Deep Blue retrieval method (e.g., Hsu et al., 2006). Here, we concentrate only on the dark-target portion. Both dark target pieces are conceptually similar, and are designed for retrieval over targets that are "dark" in the visible. Since launch, both pieces (land and ocean separately) of the dark-target algorithms has been continually evaluated, updated and improved (e.g., Remer et al., 2005; Levy et al., 2009). While the over-ocean part is fundamentally unchanged, the over land part has experienced a complete overhaul (e.g., Levy et al., 2007). The most recent versions of the algorithms have been used to derive aerosol products from the entire time series of MODIS spectral observations, known as Collection 5 (C005). These products include the total aerosol optical thickness (AOT or $\tau$, defined at $550 \mathrm{~nm}$ ), and some aspects of fine-sized aerosol contribution to the total. In practice, because the ocean surface is consistently "darker" as compared to land for wavelengths larger than $660 \mathrm{~nm}$, the over ocean algorithm requires fewer assumptions and is allowed more freedom to find solutions. Global validation exercises have indicated expected uncertainties for AOT at $550 \mathrm{~nm}$ as $\pm(0.05 \tau+0.03)$ and $\pm(0.15 \tau+0.05)$ over ocean and land, respectively (Remer et al., 2005; Levy, 2009). These total uncertainties include the uncertainties in our assumptions of aerosol optical properties, radiative transfer through the atmosphere, and errors in the computational 
aspects. The total uncertainty also includes uncertainties in assumed land surface optical properties, as well as issues of cloud masking, pixel selection, instrument calibration and precision, etc. For these details, please see Levy (2009).

Both algorithms are based on the Look Up Table (LUT) approach, where top-of-atmosphere (TOA) spectral reflectance is simulated at the appropriate wavelengths (using radiative transfer code) for a set of "expected" atmospheric/surface scenarios. These expected conditions include ambient aerosol size distributions comprised of multiple lognormal fine (radius $<1 \mu \mathrm{m}$ ) and coarse mode. Over the ocean, the LUT is calculated using the Ahmad-Fraser code (Ahmad et al., 1982), for four fine-mode aerosol types and five coarse-mode aerosol types (all nine are assumed spherical). For the operational version of the algorithm, ocean surface reflectance characteristics are assumed; for this experiment we derived a similar LUT for zero ocean surface contribution. Over land, instead of modes, each aerosol type is bilognormal (e.g., Levy et al., 2007), and based on climatology of AERONET almucantar retrievals, similar to those described by Dubovik et al. (2002). Three of them are spherical and fine-mode dominated, differing mainly by their single scattering albedos (approximately $\omega_{0}=0.86,0.91$ and 0.95 ). The scattering properties are calculated with Wiscombe's (1981) "MIEV" code. The fourth is assumed spheroid, and modeled based on collection of global coarse-dominated almuncatur retrievals of desert dust (Dubovik et al., 2006). Scattering properties of the spheroid dust is computed using the modified T-matrix "NM" code (Dubovik et al., 2006). For all over-land aerosol types, the TOA reflectances are simulated using the adding-doubling "RT3" code of Evans and Stephens (1991). Polarization effects from Rayleigh and aerosol are included in both the Ahmad-Fraser codes (over ocean) and RT3 (over land). The coupling of molecular and aerosol scattering is fully taken into account. Thus, these ocean and land LUTs can be used as inputs to their respective aerosol retrieval algorithms.

Each algorithm utilizes a subset of 7 MODIS bands in the visible (VIS), near-IR (NIR) and shortwave-infrared (SWIR) that includes $0.47,0.55,0.66,0.87,1.2,1.6$ and $2.1 \mu \mathrm{m}$. They are also known as channels 3, 4, 1, 2, 5, 6 and 7, respectively. Over ocean, LUTs are created at all seven channels, whereas over land, the LUT is created at only four (channels 3, 4, 1, and 7). Over ocean, the LUT is calculated for each of the nine aerosol types, for six loadings (AOT at $0.55 \mu \mathrm{m}$ of 0.0 , $0.2,0.5,1.0,2.0$ and 3.0), and at multiple geometrical conditions ( 9 solar zenith angles up to $72^{\circ}, 16$ view zenith angles, and 16 relative azimuths angles). Over land, the LUT is calculated for seven loadings (AOT at $0.55 \mu \mathrm{m}$ of $0.0,0.25,0.5$, 1.0, 2.0, 3.0, and 5.0) for each of the four aerosol types, also at multiple geometrical conditions (similar to ocean). For both land and ocean LUT, spectral AOT is reported based on model extinction ratios to AOT at $0.55 \mu \mathrm{m}$.

For our experiment here, we are retrieving aerosol properties from synthetic data. We use "standalone" versions of the retrieval codes, which do not require the extensive processing overhead of the operational algorithms. There are no uncertainties as to cloud masking, pixel selection, or instrument calibration. There is also no uncertainty as to surface reflectance assumptions, as we assume the surface is black at all wavelengths. Thus, we are doing "pure" aerosol retrieval, and focusing only on LUT creation, radiative transfer code, and the mathematics of the inversion/fitting processes.

Here, the input to either MODIS retrieval is synthetic geometry and spectral reflectance, in six channels over ocean (all but $0.47 \mu \mathrm{m}$ ) and in three channels over land (all but $0.55 \mu \mathrm{m})$. In action, both MODIS retrieval codes use mathematical inversion to search the LUT to find the best "match" to the observed conditions. The "solution" is the combination of total AOT at $0.55 \mu \mathrm{m}$, and fine-aerosol contribution (fine aerosol weighting, FW or $\eta$ ) that is associated with this best match. This FW is defined differently over ocean and land, where $\eta_{\mathrm{o}}$ (ocean) is the ratio of fine-mode to total radiance contributions at 0.55 , and $\eta_{1}$ (land) is the ratio of fine-dominated model (non dust) to the total. Over land, we "fixed" the fine-dominated model to the least absorbing aerosol model type (SSA 0.95 ) and the coarse type to dust, but over ocean, the retrieval was free to pick the combination of one fine mode type $\left(i_{\mathrm{f}}\right)$ and one coarse type $\left(i_{\mathrm{c}}\right)$ that gave the best fit. Over land, the $\eta_{1}$ is incremented at 0.1 intervals $(-0.1$ to 1.1$)$ to find the best solution, whereas over ocean, $\eta_{\mathrm{o}}$ is unconstrained between the $0.0-1.0$ interval. For both algorithms, the solution also includes the residual of the matching $(\varepsilon)$. In addition to these retrieved solution products, the algorithm uses the LUT to provide spectral AOT $\left(\tau_{0}\right)$ and Angstrom exponent $(\alpha)$.

The aerosol algorithms described here do not derive the phase function nor the single scattering albedo. Because it operates over a wider spectral range, and the surface reflectance is better constrained, the ocean algorithm has better sensitivity to the size and phase function. However, both algorithms operate pixel by pixel and have limited choices of aerosol type. If "actual" aerosol properties are too different from those assumed, then the retrieved products will be less accurate.

\subsection{MERIS}

For many years, all main operational techniques to retrieve spectral aerosol optical thickness from satellite data include radiative transfer (RT) in the data processing using look-uptable. As is known the main advantage of this technique is time saving. But increasing information provided by satellite sensors (multi-angle, multi-spectral data, polarization measurements) opens the possibility to use various statistical optimizations in satellite data processing. With this in view a few years ago the aerosol retrieval techniques that use radiative transfer computations in the process of the AOT retrieval rather than LUT have been developed. In this case the derivatives of radiative characteristics over retrieved values 
should be computed in the process of the retrieval. Such approach can be applied operationally only if the accurate and extremely fast radiative transfer code is used. The RAY code (Tynes et al., 2001; Katsev et al., 2009) for simulation of the radiative transfer in the atmosphere-underlying surface system was used. This code is fast. Also it has a high accuracy. RAY's high processing speed allows use of iterative radiation transfer computations in the processing of satellite data for the AOT retrieval, eliminating the need for LUT techniques.

The RAY code is assigned to calculate radiance and polarization of radiation in UV, visible and IR spectral ranges in atmosphere-ocean and atmosphere-land systems including any aerosol and gas models and bi-directional reflectivity of underlying surfaces. It has been applied with success for the solution of many problems. Accurate and extremely fast computations with RAY along with a possibility of detailed and realistic modeling of light scattering media are due to the used original algorithm, which couples the earlier developed two-component approach (Zege et al., 1993) of the vector radiative transfer theory with the traditional adding-doubling technique. The basic method used, the two-component approach, is the principal source of the saving computation time practically without a loss of accuracy. The accurate semi-analytical solution is used for the small-angle part of the Green's matrix (Zege et al., 1996). Additionally a few findings of RT theory are used to speed up the traditional adding-doubling technique. As a result RAY meets the speed requirements for including RT computations in the AOT retrieval processing. Validation of the RAY code has demonstrated (Tynes et al., 2001) that it provides highly accurate data in a fraction of the time required by the Monte Carlo and other methods. For instance, the difference between RAY and SCIATRAN computations for aerosol atmosphere is smaller than $0.5 \%$ for all Stokes vector components (see benchmark results at http://www.iup.physik.uni-bremen.de/ $\sim$ alexk).

The first simple implementation of the idea of using RT computations in the process of the retrieval was realized as the ART code for AOT and Angstrom exponent retrieval from MERIS data with least mean square optimization (Katsev et al., 2009). In the ART algorithm developed at the National Academy of Sciences of Belarus (NASB) the model of the stratified atmosphere is taken as two coupled layers. Both layers include aerosol scattering and absorption, molecular scattering, and gas absorption.

The layer " 1 " (lower layer) of the atmosphere is a comparatively thin layer of the lower troposphere up to the height $H$. As the aerosol in this layer is characterized by maximal spatial and temporal variations, the AOT of this layer is supposed to vary from pixel to pixel and is retrieved for each pixel independently. Stratification in this layer is neglected. The performed computations showed that the ignorance of the stratification inside the layer " 1 " leads to the relative error of calculations of the reflectance at the top of atmosphere less than $0.2 \%$ for any wavelength in the visible.
The layer "2" (upper layer, i.e. the atmosphere above the altitude $H$ ) includes the stratosphere and upper and middle troposphere. Naturally, the layer " 2 " is characterized by the vertical stratification of aerosol and gases concentrations, pressure and temperature profiles. For computation, this layer is presented as $N$ homogenous sub-layers with optical characteristics averaged over each sub-layer. For example, the used LOWTRAN Mid-Latitude Summer atmosphere model consists of 48 layers. The radiation characteristics of the stratified layer "2" are computed one time for all pixels of the processing frame. This feature reduces the computation volume considerably. For the layer " 2 ", the reflectances at the illumination from the top $R_{2}\left(\mu, \mu_{0}, \varphi\right)$ and from the bottom $R_{2}^{*}\left(\mu, \mu_{0}, \varphi\right)$ as well as the transmittance at the illumination from the bottom $T_{2}^{*}\left(\mu, \mu_{0}, \varphi\right)$ are computed with the RAY code. Here $\mu_{0}$ and $\mu$ are cosines of the incidence and observation zenith angles, $\varphi$ is a difference between the azimuth angles of the incidence and observation directions. To be more specific, the azimuth Fourier harmonics of the reflectances $R_{2}^{(k)}\left(\mu, \mu_{0}\right), R_{2}^{*(k)}\left(\mu, \mu_{0}\right)$, and the transmittance $T_{2}^{*(k)}\left(\mu, \mu_{0}\right)(k$ counts the azimuth harmonics) are computed in the doubling scheme and used in the retrieval procedure to include the radiative interaction between the layers " 1 " and "2".

The spectral optical thickness of the total aerosol atmosphere is the sum of the aerosol optical thicknesses of the layer "1" and layer "2", respectively. The model of the land spectral albedo $r(\lambda)$ is taken as a linear combination of some basic spectra of the vegetation $r_{\mathrm{veg}}(\lambda)$ and soil $r_{\text {soil }}(\lambda): r(\lambda)=c r_{\text {veg }}(\lambda)+(1-c) r_{\text {soil }}(\lambda)$, where we used the basic spectra $r_{\mathrm{veg}}(\lambda)$ and $r_{\text {soil }}(\lambda)$ given by von HoyningenHuene et al. (2003). Thus, the spectral albedo of the surface is characterized by the only parameter $c$ in the framework of our retrieval approach. The possible surface bidirectional reflectance effects are ignored. The normalized differential vegetation index for the "land" pixels serves as a zero approximation for the mixing parameter $c$ and is estimated for each pixel.

With the assumption of the Angstrom law for the aerosol optical thickness of the layer " 1 " $\tau_{1}(\lambda)=\beta \lambda^{-\alpha}$, the only three values should be retrieved, namely aerosol optical thickness $\tau_{1}(\lambda)$ at some wavelength, Angstrom exponent $\alpha$ for the layer " 1 ", and the parameter $c$. In our algorithm, parameters $\tau_{1}(412 \mathrm{~nm}), \alpha, c$ are computed using MERIS data for $R_{\mathrm{TOA}}(\lambda)$ in 7 spectral channels centered at $412.5,442.5,490$, $510,560,620$, and $665 \mathrm{~nm}$.

The core of the ART algorithm is the optimization of the parameters $\tau_{412}, \alpha, c$ in the iteration process. These parameters do not depend on the wavelength by definition and are derived with use the least mean square method by the iteration process as described by Katsev et al. (2009). The spectral albedo of land $r_{\mathrm{s}}(\lambda)$ is calculated with the new corrected model of tropospheric aerosol and retrieved dependence $\tau_{1}(\lambda)$. The described iteration process with use 
of least mean square technique and derivatives is very effective due to use of the RT code in the process of the retrieval.

Thus, the AOT retrieval with ART being comparable in the processing time with other operatonal techniques has the following peculiarities:

- ART uses minimal simplifications in the computation of the radiative transfer through atmosphere, for instance, accurately accounts for the interaction between atmospheric layers, for the effect of polarization on radiances;

- the AOT and Angstrom exponent are optimized using the least mean square technique (RAY provides fast computation of the derivatives with respect to retrieved values);

- any set of wavelengths and also data of many satellite optical instruments can be processed without many changes in ART code;

- atmospheric model can be easily changed in the retrieval process.

The verification of the ART retrieval technique performed by comparing with AERONET data and results of AOT retrieval obtained with use of other retrieval techniques have shown ART reasonable accuracy. The ART technique is at least as accurate as other widely used approaches (for details, see Katsev et al., 2009).

It is important that using RT calculations with the statistical optimization in the satellite data processing is the more efficient the more information (polarization, angular, spectral) is available.

\subsection{AATSR}

\subsubsection{Oxford University algorithm}

The aerosol component of the Oxford-RAL Aerosol and Cloud (ORAC) retrieval scheme has been described in detail by, most recently, Thomas et al. (2009a,b). In this work the algorithm is applied to synthetic data generated using the profile of the Advanced Along Track Scanning Radiometer (AATSR). The algorithm makes use of top-of-atmosphere reflectance measurements at four bands in the visible/nearinfrared (centred near $555 \mathrm{~nm}, 660 \mathrm{~nm}, 879 \mathrm{~nm}$ and $1.6 \mu \mathrm{m}$ ) and two viewing geometries; namely, a nadir-looking view with a zenith angle of up to $22^{\circ}$, and a forward-looking view with a zenith angle of approximately $55^{\circ}$. These measurements are acquired near-simultaneously in time, with the forward scan of a scene around 2 min before the nadir scan. Spatial resolution is approximately $1 \mathrm{~km}$ at nadir, and swath width $500 \mathrm{~km}$.

ORAC is an optimal estimation retrieval (Rodgers, 2000) making use of Levenburg-Marquardt iteration (Levenberg, 1944; Marquardt, 1963) to find the most probable state of the surface and atmosphere given measured TOA reflectances and a priori information on the state. All measurements are used to simultaneously retrieve all state parameters. The retrieved parameters are the aerosol optical thickness at $550 \mathrm{~nm}$, the aerosol effective radius (ratio of third to second moments of the number size distribution) and the white-sky surface albedo at each of the four wavelengths used. The forward model uses a bidirectional reflectance distribution function (BRDF) approach to model the surface reflectance; the white-sky albedo is the retrieved quantity, although the BRDF and black-sky albedo for the pixel geometry can also be reconstructed. For this intercomparison the BRDF and albedo were fixed at zero. Additionally, an indication of the aerosol type is provided. Knowledge of the two retrieved aerosol parameters and the aerosol type allows the derivation of other quantities, such as the AOT at other wavelengths or the Angstrom exponent, and the results of the retrieval are independent of which two aerosol parameters are derived.

The robust statistical basis of the optimal estimation framework provides the following advantages:

1. pixel-by-pixel estimates of the quality of the retrieval solution (the retrieval "cost"). This is essentially an error-weighted $\chi^{2}$ test of the retrieval solution. This provides a level of confidence for the results of any retrieval.

2. pixel-by-pixel estimates of the random error on each retrieved parameter. These arise through knowledge of the uncertainty on the measurements and any a priori data, propagated through the forward model, and show how well the measurements constrain the state.

3. the ability (but not requirement) to use any a priori data available on the state parameters. Operationally, MODIS BRDF data (Wanner et al., 1997) are used over the land to fix the angular shape of the BRDF, and as an a priori value for the white-sky albedo. Similarly, each of the possible aerosol classes has its own a priori AOT and effective radius.

The retrieval forward model, presented in Thomas et al. (2009b), calculates the TOA reflectance for a given viewing geometry and state vector. It makes use of pre-calculated lookup tables of atmospheric transmission and reflectance using the DISORT radiative transfer code (Stamnes et al., 1988). These LUTs are linearly interpolated during the retrieval. A selection of aerosol models is used in the retrieval (with LUTs calculated for each), corresponding to typical continental, desert, or maritime aerosol, using aerosol components drawn from the OPAC database of Hess et al. (1998), and additionally a model for biomass burning aerosol drawn from Dubovik et al. (2002). These models consist of mixtures of aerosol components, and different effective radii are obtained by altering their mixing ratios during the retrieval. 
The retrieval is attempted for each aerosol model in turn. The aerosol type is then chosen by examination of the retrieval cost statistic for each model. The model resulting in the retrieval with the lowest cost is the best-fitting type; for low aerosol loadings, however, this measure may be unreliable as a variety of models can often fit the measurements to within their expected errors.

\subsubsection{Swansea University algorithm}

The Swansea University retrieval algorithm was designed to retrieve the aerosol optical thickness using AATSR dualview measurements in the spectral range $550-1610 \mathrm{~nm}$. The corresponding LUTs have been calculated using the scalar version of 6S code (Vermote et al., 1997) for a range of atmospheric aerosols such as the smoke aerosol, continental aerosol, dust aerosol, maritime aerosol, and urban (black carbon) aerosol. The optimum value of AOT and aerosol model is selected on the basis of best-fit of surface reflectances to the model implemented in the algorithm (North et al., 1999; North 2002), and adapted for efficient processing of global data by Grey et al. (2006a). Global validation with AERONET and other satellite sensors was presented by Grey (2006b) and Kokhanovsky et al. (2007). The algorithm has also been adapted to use the 5-angle sampling of the CHRIS-PROBA instrument (Davies et al., 2010). Recently Bevan et al. (2009) demonstrate the impact of atmospheric aerosol from biomass burning in the Amazon region in an analysis spanning the full 13-year ATSR-2/AATSR data set. The retrieval procedure was implemented within ESA's GPOD high-performance computing facility for global retrievals of AOT and bi-directional reflectance from ATSR2 and AATSR. Further details on the algorithm are given in Grey and North (2009).

The fundamental idea of this algorithm is the retrieval of atmospherically corrected surface reflectance without the explicit use of a priori assumptions on surface type or reflectance spectrum. In fact the strength of the original algorithm lies in the use of a simple model of the light scattering properties of the surface as described in detail in North $(1999,2002)$ and Grey (2006b). This model defines spectral variation of reflectance anisotropy accounting for variation in diffuse light from atmosphere and multiple scattering at the surface. The algorithm uses the combined set of the four wavelength channels and the two viewing directions (nadir, $55^{\circ}$ forward) to invert the given TOA reflectance to surface reflectance employing the $6 \mathrm{~S}$ model (version 4.1, Vermote 1997). This inversion takes into account the aerosol contribution of the TOA reflectance. The a priori aerosol parameters (AOT and aerosol model) are optimized using an error function based on fit of the derived surface reflectance to the surface model. This is in contrast to many aerosol retrievals, which optimise the atmospheric path radiance directly. For a study on synthetic AATSR spectra with the unique situation of knowing the surface reflectance exactly (black surface), the main feature of the algorithm was switched off and the square of the inverted surface reflectance was simply minimized. The minimisation involves the following steps:

- selection of one of the 5 predefined aerosol models of $6 \mathrm{~S}$ (continental, maritime, urban, desert, biomass burning).

- selection of the initial AOT and optimising AOT by iteratively inverting the TOA reflectance to surface reflectance using Brent 1D minimisation to minimise the error function simultaneously for all wavelength and viewing directions.

- this second step is repeated for all 5 aerosol models and the model with the smallest value for the error function is selected to be the optimal result of aerosol model and AOT.

Thus this version of the retrieval did not use the LUT described in Grey (2006a,b) and Bevan (2009). Instead the 6S model was run explicitly for each inversion. However the use of this retrieval version is merely a result of the necessary adjustments for the black surface and should not be significantly deviated from possible results of the LUT version.

\subsection{MISR}

\subsubsection{JPL retrieval algorithm}

The MISR Jet Propulsion Laboratory (JPL) retrieval algorithm is based on the look-up-table approach. Synthetic TOA bidirectional reflectance factors (BRFs) were used for the retrievals at the nominal MISR camera angles $\left(0.0^{\circ}, 26.1^{\circ}\right.$, $46.1^{\circ}, 60.0^{\circ}$, and $\left.70.5^{\circ}\right)$ in the principal plane $\left(0^{\circ}\right.$ and $180^{\circ}$ azimuth). BRFs were given for four wavelengths: $443 \mathrm{~nm}$, $560 \mathrm{~nm}, 670 \mathrm{~nm}$, and $865 \mathrm{~nm}$, which are close to the MISR band centers. The retrieval was performed using a modified version of the MISR Research Aerosol Retrieval algorithm described in Kahn et al. (2001, 2007). Like the MISR Standard Aerosol Retrieval algorithm, which is used operationally to produce the global MISR aerosol product (see Martonchik et al., 1998), the radiative transfer model is based on the Grant and Hunt (1968) matrix operator method, which is an implementation of the doubling/adding approach. The production version of the MISR aerosol retrieval code is not designed to handle datasets such as the one supplied for the analysis in this paper (see Sects. 2 and 3). The Research Aerosol Retrieval, on the other hand, provides greater flexibility in terms of both data input and output.

For the purposes of the analysis, it was assumed that the Sun was to the south of the instrument, so an azimuth angle of $0^{\circ}$ represented forward scattering and $180^{\circ}$ represented backward scattering. This geometry is never observed by the MISR instrument from the Terra orbit, so the Research Aerosol Retrieval algorithm was adapted to handle this geometry. In practice, the retrieval allows either an ocean surface or a reflective surface with specific constraints on the 
scattering properties to be used as the lower boundary condition. Minor modifications were made to enable a completely black surface and to include cameras that would normally be excluded because of Sun glitter. In the MISR Standard (operational) Aerosol Retrieval algorithm the two longest wavelengths are currently used over ocean, and all four bands are used over land. All four bands were used for this study. The MISR radiative transfer code is not a vector code, but it does include a correction for polarization due to Rayleigh scattering in the path radiance field. This is done by subtracting the scalar Rayleigh scattering contribution and then adding back its contribution as calculated from a vector code.

MISR aerosol retrievals are performed by comparing observed equivalent reflectances to TOA equivalent reflectances generated from the forward radiative transfer calculation with specified aerosol models. The current version of the operational MISR aerosol retrieval (Version 22) uses a set of 74 aerosol mixtures that are made up of combinations of up to three individual aerosol components. These "pure particles" represent a single aerosol component type (e.g., sulfate) with a specific refractive index and a lognormal size distribution. The archived parameters describing the distributions include the characteristic width $\sigma$; the natural logarithm of $\sigma$ is the $s$ parameter shown in Eq. (1). The 74 aerosol mixtures are based on a total of eight pure particle components: 3 non-absorbing spherical aerosol models with particle effective radii of $0.06,0.26$, and $2.80 \mu \mathrm{m} ; 3$ spherical aerosol models with particle effective radius of $0.12 \mu \mathrm{m}$ and green band single scattering albedos of 1.0, 0.9, and 0.8; and 2 nonspherical dust models. TOA radiances for aerosol mixtures use the modified linear mixing algorithm described in Abdou et al. (1997). This approach is more accurate than standard linear mixing when there is a large variation in the single scattering albedos of the component aerosols. The Research Aerosol Retrieval was configured to take each of the 74 aerosol mixtures and generate a lookup table based on the given geometry with each mixture incremented in green band aerosol optical thickness steps of 0.02 in the range 0.0 to 5.0. However, as discussed in Sect. 5 (Results), the goodness of fit metrics for the cases where moderate to high optical depths were retrieved show that the standard 74 mixtures produce poor fits. Consequently, in an attempt to find a better agreement with the synthetic data, we supplemented the aforementioned pure particles with distributions having effective radii of 0.57 and $1.28 \mu \mathrm{m}$.

\subsubsection{PSI retrieval algorithm}

Numerous MISR operational products are available, in particular geo-rectified radiance (275 and $1100 \mathrm{~m}$ resolution, depending on camera and spectral band), optical and microphysical properties of standard aerosol components and mixtures, best fit aerosol optical thickness and best fit aerosol mixture (Diner et al., 1998; NASA/ASDC, 2002). The MISR aerosol product $(17.6 \mathrm{~km}$ resolution), however, is too coarse for studies in complex domains. A novel algorithm developed at the Paul Scherrer Institute (PSI, Switzerland) is capable of retrieving simultaneously ground level extinction coefficient (for the assumed boundary layer height), AOT, aerosol mixture and surface reflectance on a resolution of $1.1 \mathrm{~km}$. Details are given in Keller et al. (2007).

The algorithm is based on the scalar radiative transfer model MODTRAN 4 (Berk et al., 1999, 2003). Aerosol optical and microphysical properties are specified in the model input. In the MISR data set used for this inter-comparison there are 11 pre-defined aerosol models, which are combined to 24 aerosol mixtures. Radiance look-up tables are calculated for each MISR mixture, spectral band and for the view geometry of each camera ( $\mathrm{cam})$. The basic aerosol related quantity used as variable input is the aerosol extinction coefficient at $550 \mathrm{~nm}, K_{\text {ext }}(550 \mathrm{~nm})$, specified for the lowest aerosol layer (currently kept constant at $1500 \mathrm{~m}$ above the ground level). The variable surface reflectance $\rho_{\text {surf }}$ is supposed to be Lambertian in this study.

In the next step, characteristic functions $\rho_{\text {surf }}=f_{\lambda \text {, cam }}$ $\left(K_{\text {ext }}(550 \mathrm{~nm})\right)$ are generated for each camera and spectral band. These functions are derived from observed camera and wavelength dependent radiances $L(\lambda$, cam) by interpolating the LUT radiances at the specified reference values $K_{\text {ext,ref }}(550 \mathrm{~nm})$. They mutually intersect at 36 data pairs $\left(\rho_{\text {surf }}, K_{\text {ext }}(550 \mathrm{~nm})\right)$. In theory, i.e., if the model assumptions are the same as in reality, those intersections coincide in one single point. In reality, however, the intersections may scatter substantially depending on the choice of the (usually unknown) parameterization. For each wavelength $\rho_{\text {surf }}$ and $K_{\text {ext }}(550 \mathrm{~nm})$ are averaged, the number of intersections used being usually less than 36 .

Note that $K_{\text {ext }}(550 \mathrm{~nm})$ should not vary with wavelength since it controls the ground level aerosol concentration in MODTRAN 4. Hence, those aerosol properties are taken as realistic for which the four $K_{\text {ext }}(550 \mathrm{~nm})$ values scatter least (best fit mixture). Eventually, the extinction coefficients of the 4 spectral bands are averaged. A MODTRAN 4 run in the transmission mode yields AOT $(550 \mathrm{~nm})$. The spectral dependences $K_{\text {ext }}(\lambda)$ and AOT $(\lambda)$ relative to $K_{\text {ext }}(550 \mathrm{~nm})$ and AOT $(550 \mathrm{~nm})$ are specified in the MODTRAN 4 input.

The retrieved extinction coefficient depends on the choice of the top height of the lowest aerosol layer. For instance, if this height were $1000 \mathrm{~m}, K_{\text {ext }}(550 \mathrm{~nm})$ would be about 1.5 times the value for $1500 \mathrm{~m}$. AOT, however remains roughly the same.

It is worth mentioning that the multiangle view algorithm yields a best fit surface reflectance as well. Hence, the surface reflectance for this inter-comparison is supposed to be Lambertian, but not necessarily black. The retrieved best fit surface reflectance should be close to zero due to the assumptions in the forward model used in this study. Actually, from the algorithm very small values of $\rho_{\text {surf }}$ were derived. If there is no clustering of the intersections (e.g., if the model parameterization substantially differs from reality), only the nadir 
viewing camera is used and $\rho_{\text {surf }}=0$ is set. This happened at $\tau>1$ for the cases specified in this work.

\subsection{POLDER/PARASOL}

\subsubsection{LOA-1 algorithm}

The inversion is based on the LUT approach, where the reflected radiances are simulated for a large range of atmospheric conditions. Then the aerosol parameters are adjusted to provide the best agreement between the measurements and the LUT values. The forward model uses the successive orders of scattering method to solve the radiative transfer within the atmosphere (Lenoble et al., 2007) considering realistic surfaces as boundary conditions (Cox and Munk, 1954; Nadal and Bréon, 1999). The combination of spectraldirectional and polarized signatures provides a very strong constraint to invert the aerosol load and characteristics. As for all Earth observing radiometers that operate in the visible spectral range, the measurements can be interpreted in terms of aerosol load but the number of derived column aerosol properties depends on the surface type.

\section{Retrievals over ocean}

The inversion scheme mainly uses the normalized radiances in the $865 \mathrm{~nm}$ channel, where the ocean color reflectance is assumed to be zero, and in the $670 \mathrm{~nm}$ channel with a constant water reflectance of 0.001 . The polarized Stokes parameters at 865 and $670 \mathrm{~nm}$ are also used for deriving the best aerosol model. Given a small $\left(\tau_{\mathrm{S}}\right)$ and a large $\left(\tau_{\mathrm{L}}\right)$ mode of particles with optical thickness $\tau=\tau_{\mathrm{L}}+\tau_{\mathrm{S}}$, the corresponding reflectance is calculated according to the approximation of Wang and Gordon (1994) by

$$
R(\tau)=c R_{\mathrm{S}}(\tau)+(1-c) R_{\mathrm{L}}(\tau)
$$

where $R_{\mathrm{S}}$ is the reflectance for the small mode and $R_{\mathrm{L}}$ is the reflectance for the large mode, both calculated for the optical thickness of the mixture, $c=\tau_{\mathrm{S}} / \tau$ is the concentration of the small mode in terms of the optical thickness. Similar equations can be written for the normalized Stokes parameters $Q_{\mathrm{R}}$ and $U_{\mathrm{R}}$.

Computations are usually performed with a rough ocean surface (Cox and Munk, 1954) and a wind speed of $5 \mathrm{~m} \mathrm{~s}^{-1}$. The foam contribution is calculated according to the Koepke's model (1984) and a constant value 0.22 of foam reflectance. A glint mask is also applied based on the computation of the reflectances using the wind speed as an input to the Cox and Munk model.

Concerning the aerosol models, the parameters are

- For the small mode, we assume that the PSD (1) width parameter $s=0.46$, four radii $a_{0}(0.04,0.06,0.08$, and $0.13 \mu \mathrm{m})$ and 3 real refractive indices $(m=1.35,1.45$ and 1.60).
- The mode of large particles (L) consists of a mixture of lognormally-distributed spherical particles of refractive index $m_{\mathrm{L}}$, with non-spherical particles. The model of non-spherical particles is the mean model given in Volten et al. (2001). For the large mode of spherical particles, we assume that $s=0.69, a_{0}=0.75 \mu \mathrm{m}$ and three real refractive indices $(m=1.33,1.35$ and 1.37). Accordingly, two optical thicknesses for the large mode at $865 \mathrm{~nm}$ are derived, $\tau_{\mathrm{L}-\mathrm{S}}$ and $\tau_{\mathrm{L}-\mathrm{NS}}$, with $\tau_{\mathrm{L}}=$ $\tau_{\mathrm{L}-\mathrm{S}}+\tau_{\mathrm{L}-\mathrm{NS}}$

Outputs of the algorithm are:

- total aerosol optical thickness and the fraction of fine particles within the accumulation mode,

- Angstrom coefficient, as an indicator of particle size,

- when the viewing geometry is suitable, POLDER/PARASOL can discriminate large spherical marine aerosols from non-spherical desert aerosols, retrieve the effective radius of the accumulation and the total size distribution. An estimate of the real part of the refractive index is also provided(tentative).

Limitations of the algorithm are:

- when the aerosol content is low, we consider a fixed aerosol model for which the aerosol optical thickness is derived.

- the retrieval of the refractive indices and modal radii of the small and large spherical particles depends on the viewing conditions since it requires a scattering angle coverage larger than $125^{\circ}-155^{\circ}$.

\section{Retrievals over land}

Aerosol remote sensing over land from visible radiance measurements is more difficult than over ocean because the surface reflectances are generally much larger than the aerosol ones, except over dark surfaces like vegetation in the blue channel, for instance. Airborne experiments have shown that the relative contribution of the surface compared to the atmosphere is less important in polarized light than in total light. So, the present aerosol algorithm over land is based on a best fit between polarized measurements and data simulated for different atmospheres (aerosol models and optical thickness) and ground surfaces conditions. The surface contribution is depending on the surface type, bare soils or vegetated areas. It can be estimated from a relationship using empirical coefficients adjusted for the different classes of land surfaces according to the main International Geosphere-Biosphere Programme biotypes and the Normalized Difference Vegetation Index (Nadal and Bréon, 1999).

Ground-based measurements of sky polarized radiances show that the aerosol polarization mainly comes from the 
small spherical particles with radii less than about $0.5 \mu \mathrm{m}$. The aerosol models used in the land algorithm consider the accumulation mode only; the contribution of the coarse mode is neglected.

Concerning the accumulation mode, the parameters are $s=0.403$, a set of ten radii $a_{0}$, from 0.05 to $0.15 \mu \mathrm{m}$, and a refractive index $m=1.47-0.01 i$. The output of the algorithm is the spectral optical thickness and Angstrom coefficient of the fine mode (over land).

The limitations of the algorithm are:

- surface models are less accurate over deserts near the horizon.

- the coarse mode can contribute to the polarization for very intense events.

\subsubsection{LOA-2 algorithm}

The new retrieval algorithm was developed by Dubovik et al. (2010) as an attempt to enhance aerosol retrieval by emphasizing statistical optimization in inversion of data from satellite sensors with high observational capabilities. Such optimization improves retrieval accuracy relying on pronounced data redundancy (excess of the measurements number over number of unknowns) that is not common in present satellites observations of aerosol with rather few exceptions. For example, the POLDER imager on board of the PARASOL micro-satellite registers, over each observed pixel, the characteristics of the reflected atmospheric radiation at up to 16 viewing directions in six spectral channels not affected by any essential gaseous absorption: $0.443,0.49,0.565$, $0.675,0.87,1.02 \mu \mathrm{m}$. In addition, the polarization of the reflected radiation is measured in three channels: $0.49,0.675$, $0.87 \mu \mathrm{m}$. Even more complete characterization of radiation from space over single pixel will be provided by Aerosol Polarimetry Sensor (APS) that is a part of currently planned Glory mission (Mishchenko et al., 2007). APS will conduct polarimetric measurements at up to $\sim 80$ viewing direction in nine channels covering spectrum from 0.41 to $2.1 \mu \mathrm{m}$.

In terms of spectral, polarimetric, and angular sampling, PARASOL, and even more so, GLORY observations have more channels than most currently operating passive satellite aerosol sensors. This provides an opportunity for more profound utilization of statistical optimization principles in satellite data inversion. Based on this strategy, the algorithm can be driven by larger number of unknown parameters and aimed at retrieval of larger number of aerosol parameters compare to most of conventional satellite retrievals.
Forward model

\section{Aerosol single scattering properties modeling}

The algorithm by Dubovik et al. (2010) does not use LUTs. Instead the algorithm retrieves an extended set of aerosol parameters following the approach implemented in the AERONET algorithm (Dubovik and King, 2000; Dubovik et al., 2006), retrieving the detailed aerosol properties from ground-based sun-photometer observations. In this approach, the aerosol is modeled as a mixture of two aerosol components (spherical and non-spherical). The nonspherical component is a mixture of polydisperse randomlyoriented spheroids (Mishchenko et al., 1997) with a sizeindependent shape (axis ratio) distribution fixed to one achieved by a best fit of spheroid mixtures to laboratory measurements (Volten et al., 2001) as described by Dubovik et al. (2006). The scattering matrices of both spherical and non-spherical components are driven by values of aerosol volume size distribution $d V\left(a_{i}\right) / d \ln a$ in 22 (this number can be changed) logarithmically equidistant points $a_{i}$ and values of real $n$ and imaginary $k$ parts of complex refractive indices given at the wavelengths of the observations. The calculations are performed using a software package developed by Dubovik et al. (2006). It uses the look-up tables of quadrature coefficients for the extinction and absorption cross-sections and scattering matrices computed using the exact T-matrix method (Mishchenko et al., 2002), and the approximate geometric-optics-integral-equation method of Yang and Liou (1996). The calculations were done for spheroids with axis ratio ranging from $\sim 0.3$ (flattened spheroids) to $\sim 3.0$ (elongated spheroids) and for 41 narrow size bins covering the size-parameter range from $\sim 0.012$ to $\sim 625$. The look-up tables were arranged into a software package, which allows fast, accurate, and flexible modeling of scattering by randomly oriented spheroids with different size and shape distributions. Thus, the algorithm is driven by:

- 22 values of $d V\left(a_{i}\right) / d \ln a$;

- $N_{\lambda}$ values of real $n\left(\lambda_{i}\right)$ part of the refractive index $(1.33 \leq n \leq 1.6) ; N_{\lambda}$ is the number of channels;

- $N_{\lambda}$ values of complex $k\left(\lambda_{i}\right)$ part of the refractive index $(0.0005 \leq k \leq 0.5)$;

- the "sphericity parameter" characterizing the proportion of spherical particles in the aerosol mixture.

\section{Accounting for multiple scattering effects}

Accounting for multiple scattering effects in the atmosphere is performed using successive orders of scattering radiative transfer code (Lenoble et al., 2007) in a similar way as is implemented in the LOA-1 algorithm, with the difference that 
Table 2. The radiative transfer models used in this study.

\begin{tabular}{|c|c|c|c|c|c|}
\hline Instrument & Team & Code & Reference & Polarization & Retrieval \\
\hline $\begin{array}{l}\text { MODIS } \\
\text { (over land algorithm) }\end{array}$ & NASA & RT3 adding-doubling & Evans and Stephens (1991) & yes & LUT/goodness of fit \\
\hline $\begin{array}{l}\text { MODIS } \\
\text { (over ocean algorithm) }\end{array}$ & NASA & $\begin{array}{l}\text { Gauss-Seidel iterative } \\
\text { technique }\end{array}$ & Ahmad and Fraser (1982) & no & LUT/goodness of fit \\
\hline MERIS & NASB & RAY fast adding-doubling & Katsev et al. (2009) & yes & $\begin{array}{l}\text { direct RT calculations/ } \\
\text { least square method }\end{array}$ \\
\hline AATSR & SU & $\begin{array}{l}6 \mathrm{~S} \text { successive orders } \\
\text { of scattering }\end{array}$ & Vermote et al. (1997) & no & $\begin{array}{l}\text { direct RT calculations/ } \\
\text { goodness of fit }\end{array}$ \\
\hline AATSR & $\mathrm{OU}$ & DISORT discrete ordinates & Stamnes et al. (1988) & no & LUT/optimal estimation \\
\hline MISR & JPL & $\begin{array}{l}\text { Matrix operator } \\
\text { doubling-adding }\end{array}$ & Grant and Hunt (1968) & $\begin{array}{l}\text { Rayleigh } \\
\text { correction only }\end{array}$ & LUT/ goodness of fit \\
\hline MISR & PSI & MODTRAN4 discrete ordinates & Berk et al. (2003) & no & $\begin{array}{l}\text { LUT/an optimum intersection } \\
\text { search }\end{array}$ \\
\hline POLDER & LOA-1 & $\begin{array}{l}\text { SOS successive orders } \\
\text { of scattering }\end{array}$ & Lenoble et al. (2007) & yes & LUT/ goodness of fit \\
\hline POLDER & LOA-2 & $\begin{array}{l}\text { SOS successive orders } \\
\text { of scattering }\end{array}$ & Lenoble et al. (2007) & yes & $\begin{array}{l}\text { direct RT calculations/statistical } \\
\text { optimization (multi-term LSM) }\end{array}$ \\
\hline
\end{tabular}

the retrieval algorithm over land uses measurements of both polarized and total reflectance. The effects of land surface reflectance are simulated using the models of bi-directional total reflectance similar to those that currently utilized in the MISR and MODIS retrieval algorithms. The directionality of polarized surface reflectance is accounted for in the similar way as the current PARASOL algorithm (Nadal and Bréon, 1999; Deuze et al., 2001). The parameters of both the total and polarized reflectance are retrieved together with aerosol parameters.

\section{Inversion}

In contrast to most of the existing satellite retrieval algorithms, this is one of the first attempts to develop aerosol satellite retrieval as statistically optimized multi-variable fitting. It is based on the inversion methodology of Dubovik and King (2002) and Dubovik (2004) that has several original (compare to standard inverse methods) features optimized for remote sensing applications. This methodology unifies the principles addressing such important aspects of inversion optimization as accounting for errors in the data used, inverting multi-source data with different levels of accuracy, accounting for a priori and ancillary information, estimating retrieval errors, clarifying potential of employing different mathematical inverse operations (e.g., comparing iterative versus matrix inversion), accelerating iterative convergence, and so on (Dubovik et al., 2010). The described concept uses the principles of statistical estimation and suggests a generalized multi-term Least Square-type formulation that complementarily unites advantages of a variety of practical inversion approaches, such as Phillips-TikhonovTwomey constrained inversion, Kalman filter, Newton-Gauss and Levenberg-Marquardt iterations. This methodology has resulted from the multi-year efforts on developing inversion algorithms for retrieving comprehensive aerosol properties from AERONET ground-based observations.

The inverse procedure is adopted with some modifications from AERONET inversion algorithm (Dubovik and King, 2000). Similarly to AERONET code, the algorithm includes:

- accounting for different levels of accuracy in the observations (e.g., for total and polarized radiances);

- various a priori constraints on retrieved aerosol properties, such as, on variability of aerosol sizes, spectral dependencies of real and imaginary refractive indices.

In difference with the AERONET retrieval, the algorithm retrieves (over land) both non-polarized and polarized surface reflectance together with aerosol properties. Therefore, it includes additionally constraints on the retrieved surface properties, e.g., a priori constraints on the spectral variability of the parameters describing non-polarized surface reflection similarly as in the studies by Sinuyk et al. (2007) and polarized directional reflectance as in studies by Nadal and Breon (1999).

The algorithm described above was run both for PARASOL and Aerosol Polarimetry Sensor (APS) on board planned NASA GLORY mission set-ups. We report here only results for PARASOL because the extension of retrievals using more wavelengths and viewing geometries (as for APS) did not bring any noticeable difference as compared to those reported for PARASOL for the case under consideration.

\subsection{Summary}

In total, in this paper we consider the comparison of 8 algorithms for 5 instruments currently operating in orbit. Three 


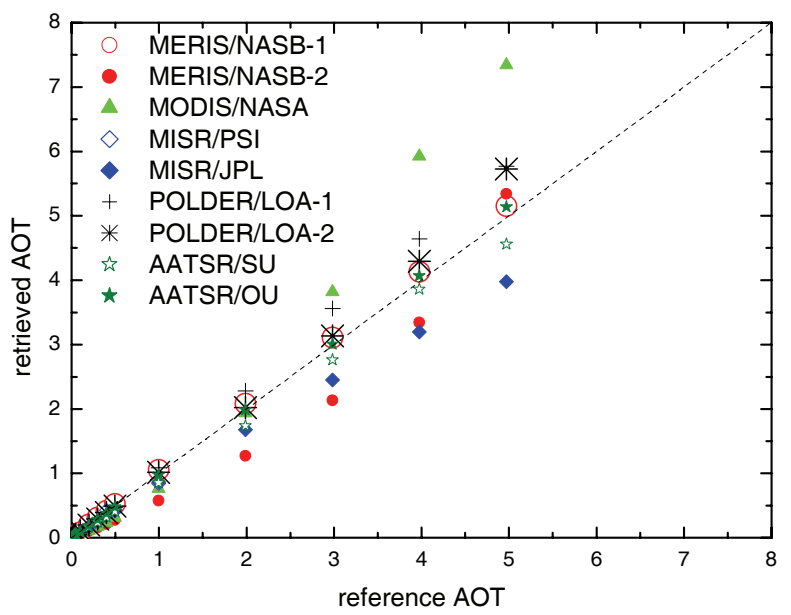

Fig. 9a. The correlation plot between the retrieved and reference AOT $(550 \mathrm{~nm})$.

algorithms use direct radiative transfer calculations during retrievals (no LUTs, see Table 2). Other algorithms are based on the look-up-table approach, where simulated radiances (or Stokes vector for the codes, which account for polarization) are pre-calculated at the intermediate stage before the retrieval process for a range of different aerosol models, which include both spherical and nonspherical models. The search in the LUT for the most suitable aerosol model is performed using various minimization techniques, including standard least squares methods and optimal estimation. In most codes LUTs are calculated only for the basic aerosol models and it is assumed that the Stokes vector (or intensity) of reflected light can be represented as a linear combination of corresponding characteristics for single modes. The parameters of the mixture are sought during the retrieval process. The radiative transfer models used in the algorithms described are quite diverse and include the following methods of the radiative transfer equation solution: adding-doubling, discrete ordinates, and successive orders scattering method. They are summarized in Table 2.

\section{Results}

In this section we consider the results of retrievals with selected algorithms as described above using the synthetic reflected light characteristics generated for the case of a plane-parallel aerosol layer $(0-2 \mathrm{~km})$ immersed in the molecular atmosphere. The aerosol model used is described in Sect. 2. The value of AOT(412 nm) was set to $\tau=0(0.01) 0.05,0.1(0.1) 0.5,1(1) 5$ depending on the scenario.

The retrieval teams for different instruments (see Table 2) were supplied only with simulated radiances and polarized radiances relevant for the given instrument; the characteristics of the underlying aerosol model were not provided to the

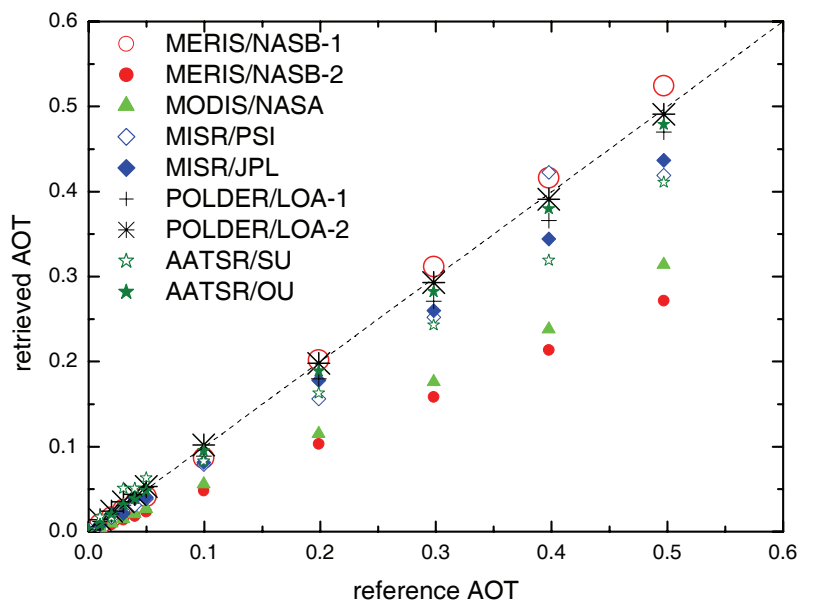

Fig. 9b. The same as in Fig. 9a except for another range of AOT $(550 \mathrm{~nm})$.

retrieval teams. The results of AOT retrievals (at $\lambda=550 \mathrm{~nm}$ ) are shown in Figs. 9-12. The following conclusions can be reached from the analysis of these figures:

- the best retrievals are achieved if not only the spectral reflectance but also the spectral second Stokes parameter is used in retrievals (for several observation directions in the principal plane). In case of reflectance only measurements, it is crucial to have a multi-angular observation capability to retrieve AOT accurately from space. MISR JPL retrievals and especially the Oxford University AATSR algorithm (the latter based on the visible and shortwave IR measurements and combining two VZAs) give very accurate results.

- methods relying on the measurements of single-angle spectral reflectance have larger theoretical retrieval errors especially if the shortwave IR measurements (as in retrievals over land for MODIS and MERIS) are not available (see, e.g., red points on Figs. 11 and 12). The MODIS retrieval algorithm over ocean does use near IR channels and, therefore, retrievals are more accurate then. As a matter of fact, the spectral methods based on the measurements in the visible only are not able to retrieve the aerosol model (at least for the case considered). Instead, they use prescribed models in the retrieval (e.g., as for NASA MODIS over land and NASB MERIS algorithm). Therefore, retrievals have been performed by the corresponding teams (NASA, NASB) for several aerosol models and those which provide results for weakly absorbing particles have been selected for plotting in Figs. 9-12. As previously mentioned, synthetic data were prepared for a weakly absorbing aerosol as well.

- the errors grow with the aerosol optical thickness (e.g., at $\mathrm{AOT}>1.0)$. This is related to several effects but 

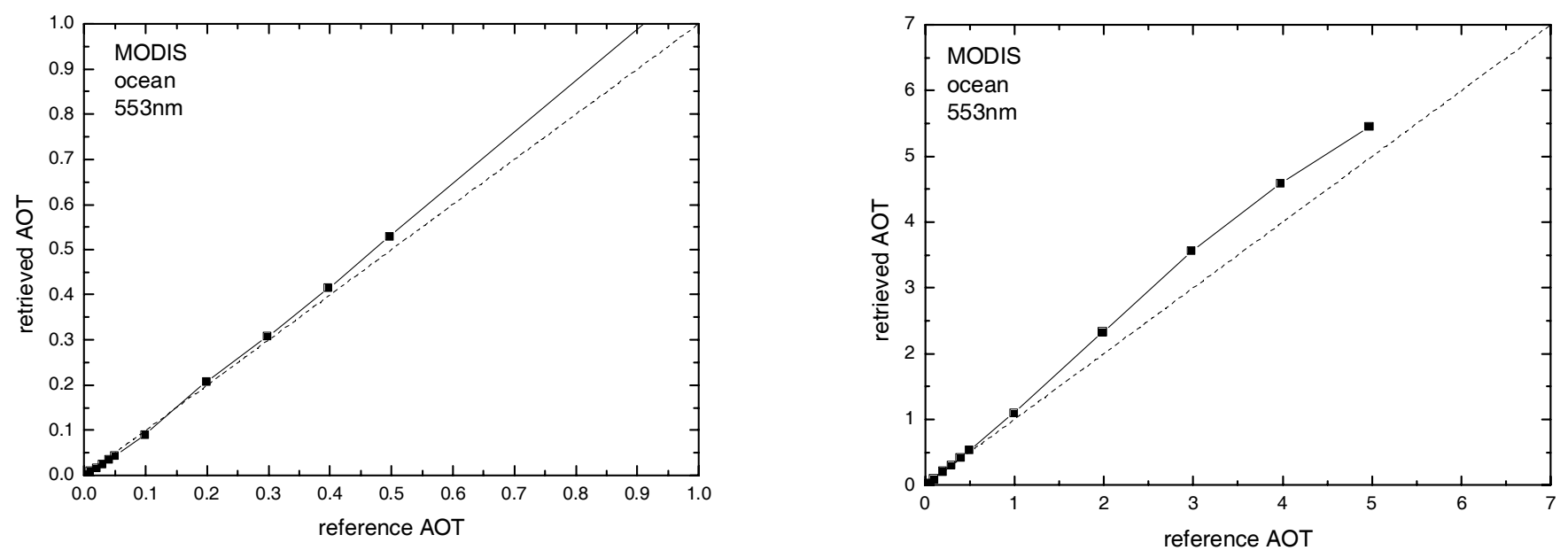

Fig. 10. The same as in Fig. 9a, b except the NASA MODIS over ocean satellite aerosol retrieval algorithm was used.

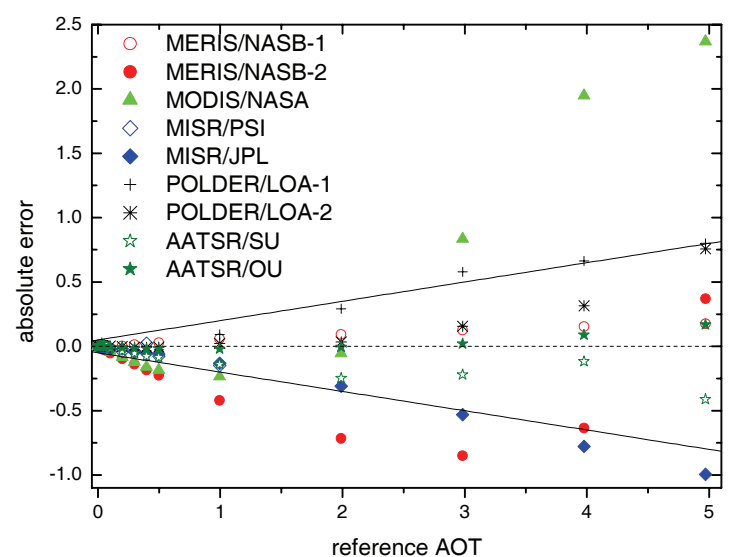

Fig. 11. The absolute errors of retrievals.

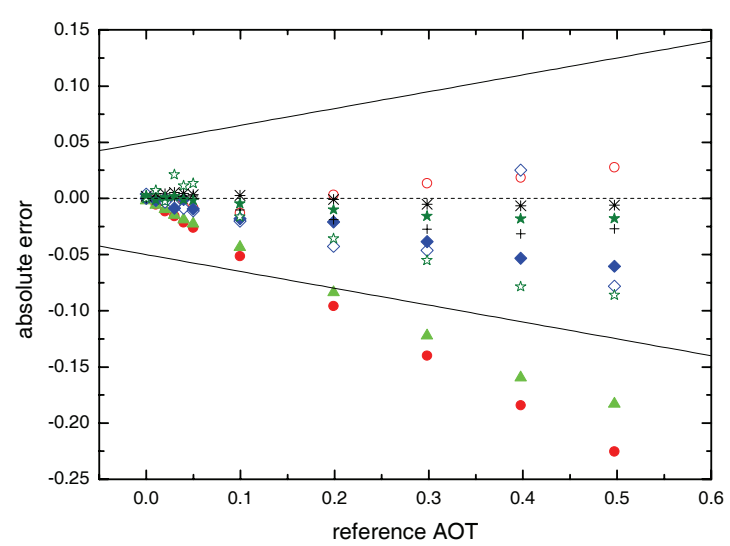

Fig. 12. The same as in Fig. 11 except for a smaller range of $\tau$.

mostly due to the general decrease of information content as resulted from the increased multiple scattering effects (smoothing of angular patterns in reflected light, light depolarization). On the other hand, multiple light scattering makes it easier to determine the single scattering albedo because absorption effects become more pronounced due to their accumulation during repeated passage of light through the same absorbing particles.

- AATSR, POLDER and MISR absolute retrieval errors are smaller than $\pm 0.05 \pm 0.15 \tau$. Absolute errors of retrievals for MODIS are somewhat larger, if the shortwave IR channels are not used in retrievals.

- NASA has two independent algorithms: one runs only for oceanic surfaces and yet another for land surfaces. The comparison of Figs. 9 and 10 shows that the oceanic algorithm performs better for the case studied. This is due to the fact that the oceanic aerosol model was selected for this inter-comparison study. This model is not in the list of the candidate aerosol models for the MODIS over land retrievals. Therefore, one can not expect high retrievals for the case considered in the case of MODIS over land algorithm, which is based on the predescribed aerosol models characteristic for continental aerosols.

The accuracy of the spectral AOT retrieval is presented in Fig. 13a. The results of LOA-2 retrievals are almost indistinguishable from the reference spectral AOT (dashed line). LOA-1 retrievals, AATSR and MISR/JPL/PSI retrievals give somewhat smaller values of AOT as compared to the reference cases. The spectral AOT is reproduced in a correct way for the case of LOA-1,2 and also MISR/JPL and AATSR/SU retrievals. Note that MISR does not use a polarization capability but gives results similar to the LOA-1 method. This shows that not only instrumental capabilities but also the accuracy of the inversion algorithm and the logic behind it play an important role in reducing the errors (see, for example, the curve for LOA-2). The methods based on the analysis 


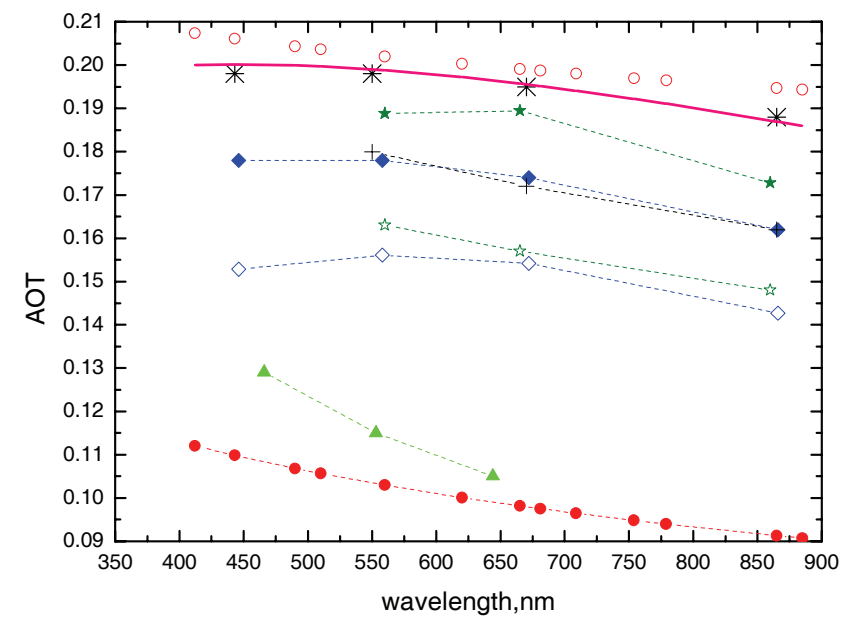

Fig. 13a. The spectral AOT according to different retrievals (the case with the reference AOT $=0.2$ at $412 \mathrm{~nm}$ ). NASB-1 retrievals have been for the oceanic aerosol and NASB-2 retrievals have been done for the water soluble aerosol (WCP-112, 1986; Kokhanovsky, 2008). The legend is the same as in Fig. 11 and the true spectral AOT is given by the pink line.

of single-angle spectral reflectance are not always capable of reproducing the AOT spectral slope in a correct way (see, e.g., red points in Fig. 13a). This is due to the fact that the correspondent aerosol model is not retrieved but rather prescribed. Excellent retrievals of the spectral AOT for the case MERIS/NASB-1 (see open circles in Fig. 13a) is due to the fact that (by chance) a correct model of the aerosol was selected in advance. If the wrong model is a priori selected, then the retrievals are biased (see filled circles in Fig. 13a). An interesting point is that the spectral MERIS reflectances calculated for both spectral AOTs (NASB-1, 2, see Fig. 13a) coincide (see Fig. 13b) one with another and also with the reference reflectance within the MERIS calibration error. This confirms that the spectral measurements in the range 400-900 $\mathrm{nm}$ (as for MERIS) can not be used to recognize the aerosol type for the case under study. There is a chance that the aerosol type can be better-constrained if shortwave IR measurements are used (see Fig. 2). This is used, in particular, by the ORAC algorithm for AATSR and also by the NASA MODIS algorithm over ocean.

The results shown in Fig. 13a are just for the reference $\operatorname{AOT}(412 \mathrm{~nm})=0.2$. In Fig. 14, the results for the spectral aerosol optical thickness are given at AOT $(412 \mathrm{~nm})$ in the range $0-1.2$. Generally, errors grow with AOT.

The MERIS ART algorithm produces quite accurate retrievals if the correct phase function is used in retrievals as shown on the upper panel of Fig. 14. MODIS over land retrievals are biased and this is due to the fact that the assumed phase function is not close to the true one. AATSR retrievals (especially using ORAC) perform much better as compared to MODIS over land algorithm. For MISR/PSI re-

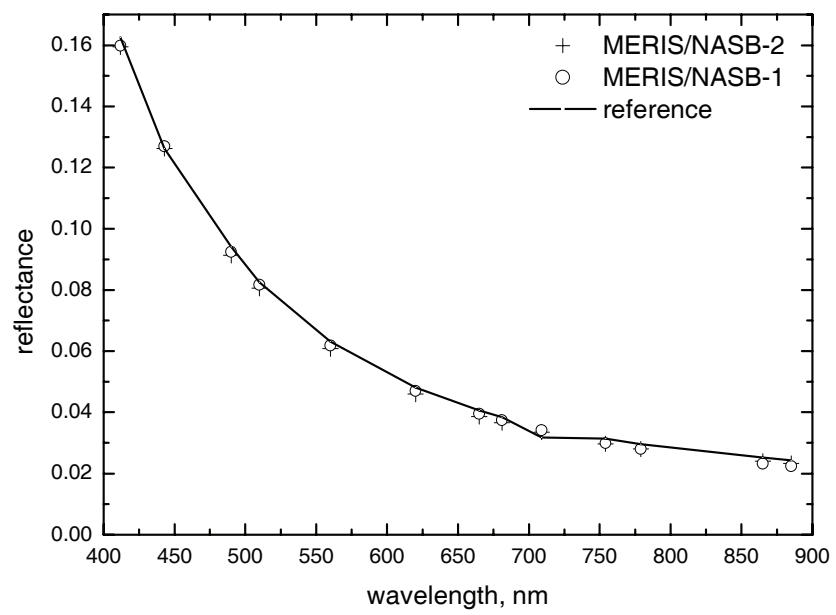

Fig. 13b. The spectral reflectance calculated using derived aerosol models (NASB-1,2) and the "true" one (solid line).

trievals there is a problem at $\tau>1$ and the multi-view PSI retrieval method is not very reliable then. This is not the case for MISR/JPL retrievals, which produce reliable results up to $\mathrm{AOT}=5$.

LOA-1 and LOA-2 methods give results very close the reference AOT with somewhat better performance of LOA2 algorithm. We found that the LOA-2 method produces a slight overestimation of the AOT at large $\tau$. This is due to the fact that the current version cannot distinguish cases with no absorption and weak absorption of radiation by aerosol particles. As a matter of fact, it is assumed in the framework of this algorithm that some dissipation of light energy always exists in the aerosol particles. Thick layers without absorption are brighter as compared to those with absorption. Therefore, POLDER LOA-2 algorithm based on absorbing aerosol models need thicker aerosol layers to produce the same level of brightness as nonabsorbing layers do. This is the reason for the discrepancy in the case of synthetic model based on the artificial nonabsorbing aerosol case studied in this work.

It is known that optically thick nonabsorbing and weakly absorbing media have very different reflectances. This is not the case for thin aerosol layers. However, this plays only a minor role in the retrievals because (with the exception of dust outbreaks) AOT $(550 \mathrm{~nm})$ is rarely above 0.4 .

It follows from Figs. 15 and 16 that the LOA-2 algorithm retrieves an accurate aerosol model and also the phase matrix elements. This is the reason behind the success of this method in the retrievals. Note that SCIATRAN was not used in the creation of the LOA-2 method look-up-tables. This indirectly confirms that both SCIATRAN and also the successive scattering method (Lenoble et al., 2007) used in the creation of LUTs for the LOA-2 retrieval produce similar results. 

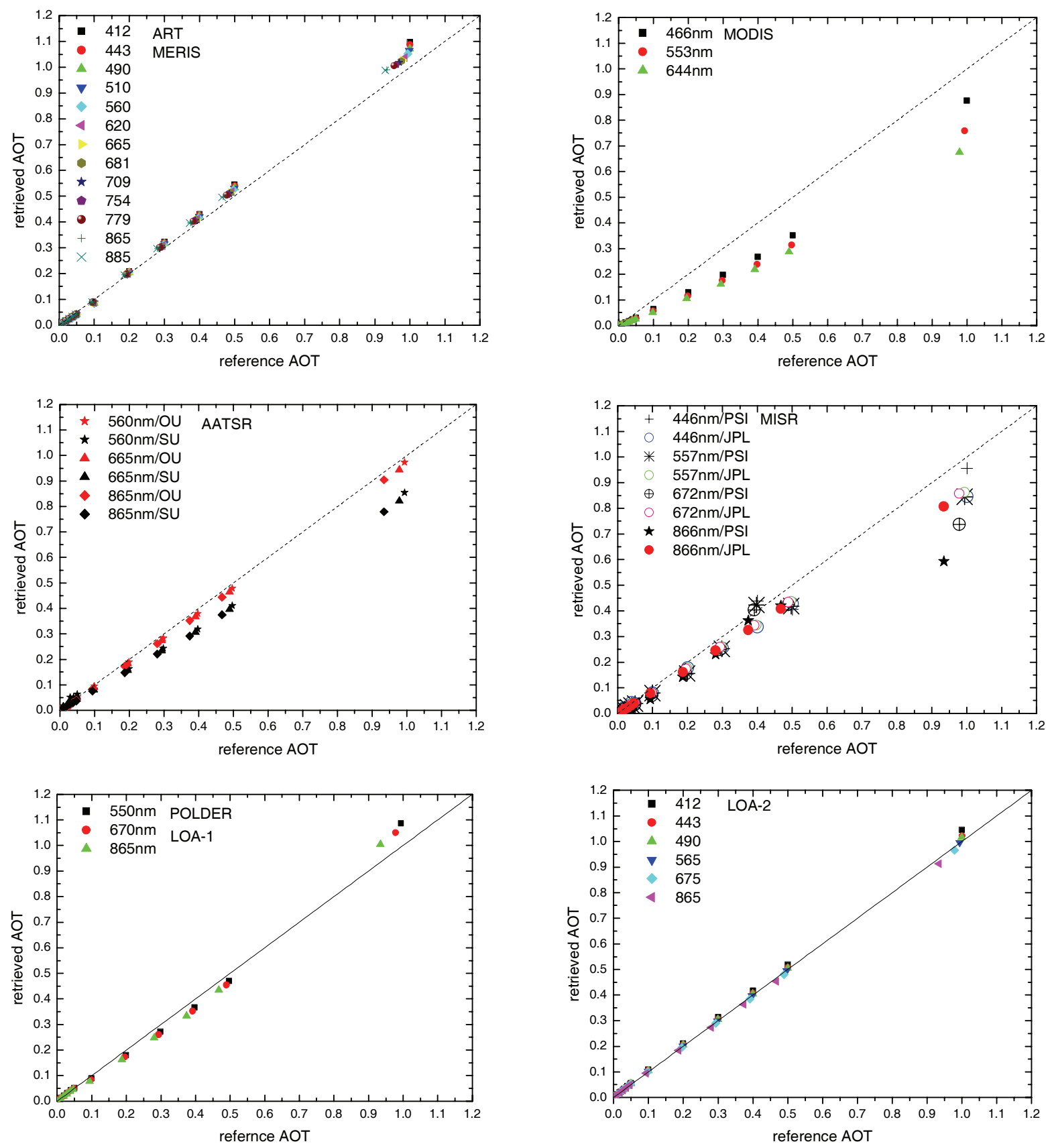

Fig. 14. The comparison of retrieved and reference spectral AOTs for different algorithms.

The phase functions for other models are given in Fig. 17. This figure confirms once more that the accurate retrieval of aerosol model and especially phase function is of paramount importance for the accuracy of the aerosol optical thickness estimations using spaceborne observations.

When the real part of the refractive index is not prescribed, it was found that almost all algorithms were able to retrieve it correctly (see Table 3). For MISR/JPL, the real part of the refractive index was not retrieved but rather prescribed. MODIS/NASA and POLDER/LOA-2 retrievals re- trieved weakly absorbing models instead of nonabsorbing (in the visible) model assumed in this work. A single-mode lognormal distribution was assumed in the creation process and this was retrieved correctly only by LOA- 2 algorithm. Other algorithms retrieved size distributions containing 2 or even 3 modes. As long as the phase function retrieved at a given observation geometry was accurate, this did not affect the retrieval accuracy of spectral AOT. The influence of error in the retrieved single scattering albedo is of importance only for thick layers. 
Table 3. The aerosol models retrieved using diverse algorithms and instruments. The parameters of the reference model are also given.

\begin{tabular}{llll}
\hline Instrument & Team & PSD parameters & $\begin{array}{l}\text { Complex refractive index } \\
\text { of the dominant mode } m\end{array}$ \\
\hline MODIS & NASA & 2 LN-modes & $1.42-0.007 i^{\mathrm{a}}$ \\
MERIS & NASB & 3 LN-modes & $1.38-10^{-8} i^{\mathrm{a}}$ \\
AATSR & SU & $2 \mathrm{LN}$-modes & $1.388-0.0003^{\mathrm{b}}$ \\
AATSR & OU & $3 \mathrm{LN}$-modes & $1.373-4 \times 10^{-9} i^{\mathrm{b}}$ \\
MISR & JPL & $2 \mathrm{LN}$-modes & $1.45^{\mathrm{b}}$ \\
MISR & PSI & $2 \mathrm{LN}$-modes & $1.45^{\mathrm{b}}$ \\
POLDER & LOA-1 & 2 LN-modes & $1.37^{\mathrm{b}}$ \\
POLDER & LOA-2 & Multi-mode & $1.38-0.0005 i^{\mathrm{c}}$ \\
Assumed reference model & & 1 mode, $a_{\mathrm{ef}}=1.21 \mu \mathrm{m}, v_{\mathrm{ef}}=1.51$ & $1.38-10^{-8} i^{\mathrm{c}}$ \\
\hline
\end{tabular}

a predefined

$\mathrm{b}$ The refractive indices of each component are predefined. The overall aerosol model does not have a predefined refractive index as it depends on the retrieved mixing ratio of the components; however, the fixed component refractive indices mean it is constrained by them.

${ }^{c}$ Smaller values of $\operatorname{Im}(\mathrm{m})$ are not allowed in retrievals in the current version of LOA-2 algorithm.

$\mathrm{d}$ The particle size distribution is not prescribed ahead of retrievals.

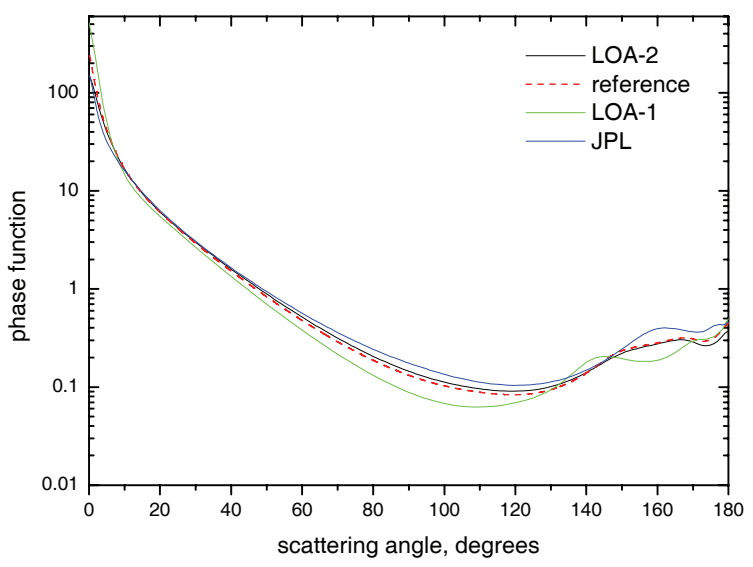

Fig. 15. The comparison of phase functions used/derived in retrievals with the reference phase function $(\lambda=550 \mathrm{~nm})$ for LOA-1,2, and JPL models.

In the case of the MISR/JPL retrievals, we found that of the standard 74 models used in the operational algorithm, even the best-fitting mixture would not have met the standard MISR operational criteria for being a good model. Using the MISR Research Aerosol Retrieval on an expanded set of mixtures (see Sect. 4.4.1), the best fitting result (called nonabsorbing 1) is a mixture (by green band optical depth fraction) of $85 \%$ of a particle distribution with effective radius $0.57 \mu \mathrm{m}$, refractive index of $1.45-0.0 \mathrm{i}$, and $\sigma=1.8(s=0.59)$, and $15 \%$ of a particle distribution having the same refractive index and effective radius $2.8 \mu \mathrm{m}, \sigma=1.90(s=0.64)$. This combination provides a good fit based on the standard criteria used to establish acceptable models. A more sensitive criterion reveals that residuals between the non-absorbing model and the synthetic data vary systematically (i.e., non- randomly) with angle and band, implying that the information content of the synthetic MISR-like data can be even further exploited. This would entail further expansion of the set of aerosol particles used in the retrievals. For example, the MISR database does not include lognormal size distributions with characteristic widths as large as the value associated with the reference model assumed in this study. Adjustment to the real refractive index - which takes on a fixed, prescribed value (1.45) in the MISR database - also improves the fits to the synthetic data.

\section{Conclusions}

The primary conclusion of this work is that accurate retrievals of aerosol optical thickness and also microphysical parameters such as refractive index/chemical composition, size/shape distributions are possible only with the use of simultaneous spectral measurements at several viewing directions of reflectance and degree of polarization of reflected solar light (Herman et al., 1997, 2005; Mishchenko and Travis, 1997; Hasekamp and Landgraf, 2007; Schutgens et al., 2004).

The dual and multi-angular measurements of spectral topof-atmosphere radiance (AATSR and MISR) also produce accurate results. However refractive index (and especially on the imaginary part) is better constrained in the case of the spectral and multi-angular Stokes vector measurements (Hasekamp and Landgraf, 2007). 

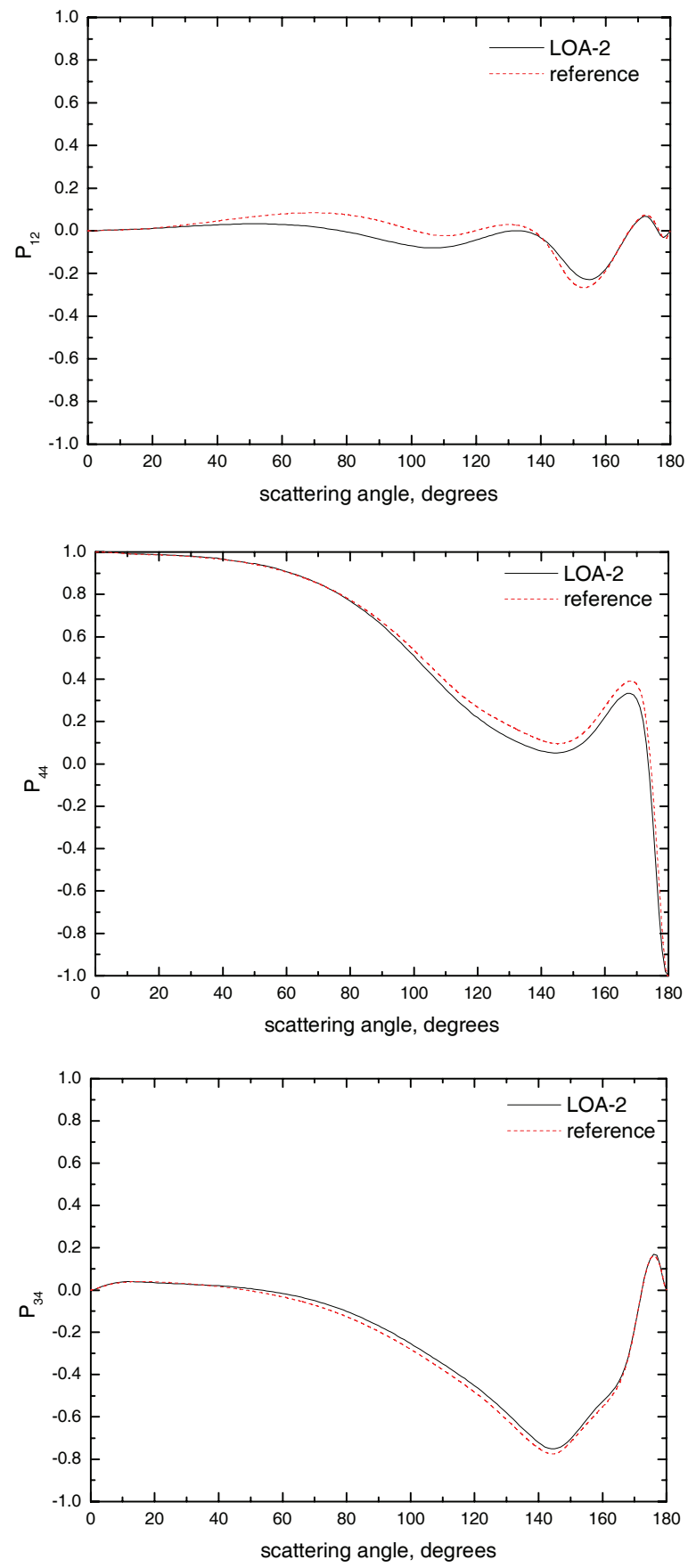

Fig. 16. The comparison of the phase matrix elements derived in retrievals by the LOA-2 algorithm with the reference phase function $(\lambda=550 \mathrm{~nm})$.

We found that the single-angle radiance measurements in the spectral range 400-900 $\mathrm{nm}$ are not sufficient to derive the aerosol model (at least for the case considerd in this paper). Currently, the aerosol model is prescribed in retrievals (for methods based on single-angle spectral reflectance measurements) using aerosol climatologies (Levy, 2009) with some success. However, climatologies refer to averages over long
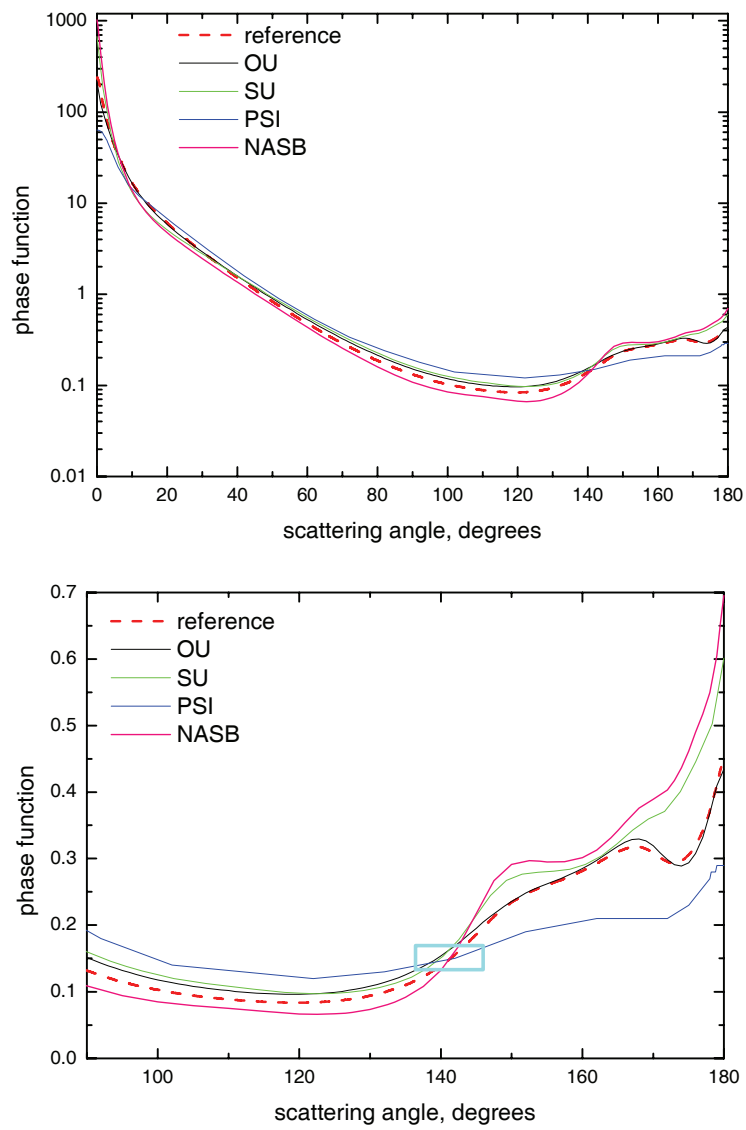

Fig. 17. The comparison of phase functions used in retrievals with the reference phase function $(\lambda=550 \mathrm{~nm})$ for ORAC, SU, PSI, and NASB retrievals. The square shows the region, where the retrievals are least sensitive to the selection of aerosol model.

time periods. Therefore, retrievals can have large biases if a different aerosol type is present at a given location and the retrievals are performed just with the assumed average properties. MODIS has a capability to measure the spectral reflectances beyond $885 \mathrm{~nm}$ channel (up to $2200 \mathrm{~nm}$ ). The use of the complete spectral information as in the MODIS over-ocean-algorithm made it possible to estimate the aerosol model and perform accurate retrieval of spectral AOT. However, the algorithm over land can not use this information due to high surface reflectance at $2200 \mathrm{~nm}$ and, therefore, MODIS over-land-algorithm has the same deficiencies as MERIS aerosol retrieval algorithm.

One important conclusion of this work is that the robust aerosol retrieval algorithms must include much more discrete aerosol models (right now MODIS over land algorithm uses just six models, e.g.). Alternatively, the retrieval must be based on the direct radiative transfer calculations with Mie cross sections and phase matrices parameterized in terms of kernels as described in Sect. 4.5.2. This will make it possible to transfer from the discrete to the continuous basis in the aerosol retrieval techniques. Another important point is the 
use of adequate radiative transfer codes, which account for the electromagnetic nature of light (polarization).

The results presented here are valid for dark underlying surfaces and apply only to the aerosol model studied. The case of bright surface (and also surface BRDF effects) requires additional investigations. We also plan to extend the range of aerosol models used in our next inter-comparison study. The synthetic data (input for the retrieval algorithms) and also the assumed aerosol model and its parameters can be downloaded from http://www.iup.physik.uni-bremen.de/ $\sim$ alexk. At the same website we provide RT benchmark results, which can be used to check the accuracy of forward radiative transfer algorithms used in corresponding retrievals.

\section{Appendix A}

Table A1. Tabular data for the aerosol model used. The spectral dependence of the normalized extinction coefficient $\kappa=K_{\text {ext }}(\lambda) / K_{\text {ext }}\left(\lambda_{0}\right) \quad\left(\lambda_{0}=412 \mathrm{~nm}\right)$. The value of $\kappa$ was equal 0.58046 at the largest wavelength $\lambda=2119 \mathrm{~nm}$ used in calculations.

\begin{tabular}{llll}
\hline$\lambda, \mathrm{nm}$ & $\kappa$ & $\lambda, \mathrm{nm}$ & $\kappa$ \\
\hline 412 & 1.00000 & 620 & 0.98612 \\
415 & 1.00012 & 644 & 0.98228 \\
427 & 1.00054 & 665 & 0.97865 \\
443 & 1.00074 & 670 & 0.97778 \\
460 & 1.00056 & 675 & 0.97690 \\
466 & 1.00053 & 681 & 0.97572 \\
485 & 0.99986 & 709 & 0.97024 \\
490 & 0.99968 & 754 & 0.96095 \\
500 & 0.99924 & 765 & 0.95848 \\
510 & 0.99863 & 779 & 0.95534 \\
516 & 0.99811 & 855 & 0.93736 \\
534 & 0.99667 & 865 & 0.93484 \\
550 & 0.99513 & 870 & 0.93361 \\
553 & 0.99478 & 885 & 0.92988 \\
555 & 0.99463 & 1243 & 0.80059 \\
560 & 0.99408 & 1632 & 0.69368 \\
615 & 0.98689 & 1670 & 0.68404 \\
\hline
\end{tabular}

www.atmos-meas-tech.net/3/909/2010/
Table A2. Tabular data for the aerosol model used. The phase function at $\lambda=550 \mathrm{~nm}$. The phase function is normalized as $\frac{1}{2} \int_{0}^{\pi} p(\theta) \sin \theta d \theta=1$ (see also http://www.iup.physik.uni-bremen.de/ $\sim$ alexk for the phase functions at all wavelengths mentioned in this paper calculated with the interval $1^{\circ}$ using Mie theory).

\begin{tabular}{ll}
\hline$\theta$, degrees & phase function \\
\hline 0 & $0.23864 \mathrm{E}+03$ \\
20 & $0.60417 \mathrm{E}+01$ \\
40 & $0.15184 \mathrm{E}+01$ \\
60 & $0.47652 \mathrm{E}+00$ \\
80 & $0.18694 \mathrm{E}+00$ \\
100 & $0.10280 \mathrm{E}+00$ \\
120 & $0.83556 \mathrm{E}-01$ \\
140 & $0.13914 \mathrm{E}+00$ \\
160 & $0.28169 \mathrm{E}+00$ \\
180 & $0.44630 \mathrm{E}+00$ \\
\hline
\end{tabular}

Table A3. Abbreviations.

\begin{tabular}{ll}
\hline AATSR & Advanced Along-Track Scanning Radiometer \\
AOT & Aerosol Optical Thickness \\
APS & Aerosol Polarimetry Sensor \\
BRDF & Bidirectional Reflectance Distribution Function \\
BRF & Bidirectional Reflectance Factor \\
DISORT & Discrete Ordinates Code \\
DFG & German Science Foundation \\
DLR & German Aerospace Centre \\
DOM & Discrete Ordinates Method \\
ESA & European Space Agency (http://www.esa.it/ \\
& export/esaCP/index.html) \\
JPL & Jet Propulsion Laboratory \\
LOA & Laboratoire d'Optique Atmospherique \\
LUT & Look Up Table \\
MERIS & Medium Resolution Imaging Spectrometer Instru- \\
& ment \\
MISR & Multiangle Imaging SpectroRadiometer \\
MODIS & Moderate Resolution Imaging Spectroradiometer \\
MC & Monte-Carlo \\
NASA & National Aeronautics and Space Administration \\
NASB & National Academy of Sciences of Belarus \\
NIES & National Institute for Environmental Studies \\
ORAC & Oxford-RAL Aerosol and Cloud retrieval \\
OU & Oxford University \\
PARASOL & Polarization and Anisotropy of Reflectances for \\
& Atmospheric Science \\
POLDER & coupled with Observations from a Lidar \\
& POLarization and Directionality of the Earth's Re- \\
PSD & flectances \\
PSI & Particle Size Distribution \\
SZA & Paul-Scherrer-Institut \\
SU & Solar Zenith Angle \\
TOA & Swansea University \\
VZA & Top of Atmosphere \\
WCP & Viewing Zenith Angle \\
\hline & World Climate Program \\
\hline &
\end{tabular}


Acknowledgements. A. A. Kokhanovsky thanks German Science Foundation (DFG) for support of this research in the framework of the Project BU-688/18-1 Terra. The research of D. J. Diner and M. Garay was performed at the Jet Propulsion Laboratory, California Institute of Technology, under a contract with the National Aeronautics and Space Administration. We thank J. Martonchik, M. Smyth, and D. Nelson of JPL and R. Kahn of the NASA Goddard Space Flight Center for technical advice and assistance with the MISR Research Retrieval calculations. The University of Oxford work was supported by the Natural Environment Research Council (grant numbers NE/F001452/1 and NE/E011187/1). Swansea University research was supported by NERC grant NE/F001436/1. J. L. Deuzé, O. Dubovik, F. Ducos, M. Herman and D. Tanré would like to thank CNES (Centre national d'études spatiales) and CNRS (Centre national de la recherche scientifique) for their support. The work of Yoshifumi Ota was performed as a part of greenhouse gases observing satellite (GOSAT) project of National Institute for Environmental Studies (NIES), which collaborates with GOSAT research announcement program conducted by A. Kokhanovsky. The authors are grateful to J. Lenoble and M. King for important comments related to this paper.

\section{Edited by: S. Kinne}

\section{References}

Abdou, W. A., Martonchik, J. V., Kahn, R. A., West, R. A., and Diner, D. J.: A modified linear-mixing method for calculating atmospheric path radiances of aerosol mixtures, J. Geophys. Res., 102, 16883-16888, 1997.

Ahmad, Z. and Fraser, R. S.: An iterative radiative transfer code for ocean-atmosphere systems, J. Atmos. Sci., 39, 656-665, 1982.

Berk, A., Anderson, G. P., Bernstein, L. S., Acharya, P. K., Dothe, H., Matthew, M. W., Adler-Golden, S. M., Chetwynd, J. H., Richtsmeier, S. C., Pukall, B., Allred, C. L., Jeong, L. S., and Hoke, M. L.: MODTRAN4 Radiative Transfer Modeling for Atmospheric Correction, SPIE Proceeding on Optical Spectroscopic Techniques and Instrumentation for Atmospheric and Space Research III, 3756, 348-353, 1999.

Berk, A., Anderson, G. P., Acharya, P. K., Hoke, M. L., Chetwynd, J. H., Bernstein, L. S., Shettle, E. P., Matthew, M. W., and Adler-Golden, S. M.: MODTRAN4 Version 3 Revision 1 User's Manual, Air Force Research Laboratory, Space Vehicles Directorate, Air Force Materiel Command, Hanscom AFB, MA 01731-3010, Hanscom, 2003.

Bevan, S. L., North, P. R. J., Grey, W. M. F., Los, S. O., and Plummer, S. E.: Impact of atmospheric aerosol from biomass burning on Amazon dry-season drought, J. Geophys. Res., 114, D09204, doi:10.1029/2008JD01111, 2009.

Cox, C. and Munk, W.: Measurements of the roughness of the sea surface from photographs of the Sun's glitter, J. Opt. Soc. Am., 44, 838-850, 1954.

Davies, W. H., North, P. R. J., Grey, W. M. F., and Barnsley, M. J.: Improvements in aerosol optical depth estimation using multiangle CHRIS/PROBA images, IEEE T. Geosci. Remote Sens., 48, 18-24, 2010.

Deuzé, J. L., Goloub, P., Herman, M., Marchand, A., Perry, G., Susana, S., and Tanré, D.: Estimate of the aerosol properties over the ocean with POLDER, J. Geophys. Res., 105, 15329-15346, 2000

Deuzé, J.-L., Bréon, F.-M., Devaux, C., Goloub, P., Herman, M., Lafrance, B., Maignan, F., Marchand, A., Nadaf, L., Perry, G., and Tanré, D.: Remote sensing of aerosols over land surfaces from POLDER-ADEOS 1 Polarized measurements, J. Geophys. Res., 106(D5), 4913-4926, 2001.

Diner, D. J., Beckert, J. C., Reilly, T. H., Bruegge, C. J., Conel, J. E., Kahn, R., Martonchik, J. V., Ackerman, T. P., Davies, R., Gerstl, S. A. W., Gordon, H. R., Muller, J.-P., Myneni, R., Sellers, R. J., Pinty, B., and Verstraete, M. M.: Multiangle Imaging SpectroRadiometer (MISR) description and experiment overview, IEEE T. Geosci. Remote, 36, 1072-1087, 1998.

Dubovik, O. and King, M. D.: A flexible inversion algorithm for retrieval of aerosol optical properties from Sun and sky radiance measurements, J. Geophys. Res., 105, 20673-20696, 2000.

Dubovik, O., Holben, B., Eck, T. F., Smirnov, A., Kaufman, Y., Kind, M., Tanre, D., and Slutsker, I.: Variability and optical properties of key aerosol types observed in worldwide locations, J. Atmos. Sci., 59, 590-608, 2002.

Dubovik, O.: Optimization of numerical inversion in photopolarimetric remote sensing, in: Photopolarimetry in Remote Sensing, edited by: Videen, G., Yatskiv, Y., and Mishchenko, M., Kluwer Academic Publishers, Dordrecht, Netherlands, 65-106, 2004.

Dubovik, O., Sinyuk, A., Lapyonok, T., Holben, B. N., Mishchenko, M., Yang, P., Eck, T. F., Volten, H., Munoz, O., Veihelmann, B., van der Zander, W. J., Leon, J.-F., Sorokin, M., and Slutsker, I.: Application of light scattering by spheroids for accounting for particle non-sphericity in remote sensing of desert dust, J. Geophys. Res., 111, D11208, doi:10.1029/2005JD006619d, 2006.

Dubovik, O., Lapyonok, T., Kaufman, Y. J., Chin, M., Ginoux, P., Kahn, R. A., and Sinyuk, A.: Retrieving global aerosol sources from satellites using inverse modeling, Atmos. Chem. Phys., 8, 209-250, doi:10.5194/acp-8-209-2008, 2008.

Dubovik, O., Herman, M., Holdak, A., Lapyonok, T., Tanré, D., Deuzé, J.-L., Ducos, F., Sinyuk, A., and Lopatin, A.: Development of statistically optimized inversion algorithm for enhanced retrieval of aerosol properties from spectral multi-angle polarimetric satellite observations, Atmos. Meas. Tech. Discuss., in preparation, 2010.

Emde, C., Buras, R., Mayer, B., and Blumthaler, M.: The impact of aerosols on polarized sky radiance: model development, validation, and applications, Atmos. Chem. Phys., 10, 383-396, doi:10.5194/acp-10-383-2010, 2010.

Evans, K. F. and Stephens, G. L.: A new polarized radiative transfer model, J. Quant Spectrosc. Ra., 46, 413-423, 1991.

Grant, I. P. and Hunt, G. E.: Solution of radiative transfer problems using the invariant $S_{n}$ method, Mon. Not. R. Astron. Soc., 141, 27-41, 1968.

Grey, W. M. F., North, P. R. J., and Los, S. O.: Computationally efficient method for retrieving aerosol optical depth from ATSR2 and AATSR data, Appl. Optics, 45(12), 2786-2795, 2006a.

Grey, W. M. F., North, P. R. J., Los, S. O., and Mitchell, R. M.: Aerosol optical depth and land surface reflectance from multiangle AATSR measurements: Global validation and inter-sensor comparisons, IEEE T. Geosci. Remote , 44(8), 2184-2197, 2006b.

Grey, W. M. F. and North, P. R. J.: Aerosol Optical 
Depth from multi-view-angle AATSR satellite observations, in: Satellite Aerosol Remote Sensing over Land, edited by: Kokhanovsky, A. A. and de Leeuw, G., Springer-Praxis, Berlin, 101-134, ISBN: 978-3-540-69396-3, 2009.

Hasekamp, O. P. and Landgraf, J.: Retrieval of aerosol properties over land surfaces: capabilities of multiple-viewing-angle intensity and polarization measurements, Appl. Optics, 46, 33323344, 2007.

Herman, M., Deuzé, J. L., Marchand, A., Roger, B., and Lallart, P.: Aerosol remote sensing from POLDER/ADEOS over the ocean: Improved retrieval using a nonspherical particle model, J. Geophys. Res, 110, D10S02, doi: 10.1029/2004JD0044798, 2005.

Herman, M., Deuzé, J. L., Devaux, C., Goloub, P., Bréon, F. M., and Tanré, D.: Remote sensing of aerosols over land surfaces including polarization measurements: applications to POLDER measurements, J. Geophys. Res., 102, 17039-17050, 1997.

Herman, M., Deuzé, J.-L., Marchand, A., Roger, B., and Lallart, P.: Aerosol remote sensing from POLDER//ADEOS over the ocean: Improved retrieval using a nonspherical particle model, J. Geophys. Res., 110, D10S02, doi:10.1029/2004JD004798, 2005.

Hess, M., Koepke, P., and Schult, I.: Optical properties of aerosols and clouds: The software package OPAC, Bull. Am. Meteorol. Soc., 79, 831-944, 1998.

Hsu, N. C., Tsay, S. C., King, M. D., and Herman, J. R.: Deep blue retrievals of Asian aerosol properties during ACE-Asia, IEEE T. Geosci. Remote, 44, 3180-3195, 2006.

Kahn, R., Banerjee, P., and McDonald, D.: Sensitivity of multiangle imaging to natural mixtures of aerosols over ocean, J. Geophys. Res., 106, 18219-18238, 2001.

Kahn, R. A., Garay, M. J., Nelson, D. L., Yau, K. K., Bull, M. A., Gaitley, B. J., Martonchik, J. V., and Levy, R. C.: Satellitederived aerosol optical depth over dark water from MISR and MODIS: Comparisons with AERONET and implications for climatological studies, J. Geophys. Res., 112, D18205, doi:10.1029/2006JD008175, 2007.

Kahn, R. A., Nelson, D. L., Garay, M. J., Levy, R. C., Bull, M. A., Diner, D. J., Martonchik, J. V., Paradise, S. R., Hansen, E. G., and Remer, L. A.: MISR aerosol product attributes, and statistical comparisons with MODIS, IEEE T. Geosci. Remote, 47, 40954114., 2009.

Katsev, I. L., Prikhach, A. S., Zege, E. P., Ivanov, A. P., and Kokhanovsky, A. A.: Iterative procedure for retrieval of spectral aerosol optical thickness and surface reflectance from satellite data using fast radiative transfer code and its application to MERIS measurements, in: Satellite Aerosol Remote Sensing over Land, edited by: Kokhanovsky, A. A. and de Leeuw, G., Springer-Praxis, Berlin, 101-134, 2009.

Kaufman, Y. J., Tanré, D., Gordon H. R., Nakajima T., Lenoble J., Frouin R., Grassl H., Herman B.M., King M., and Teillet P. M.: Operational remote sensing of tropospheric aerosol over land from EOS moderate resolution imaging spectroradiometer, J. Geophys. Res., 102(D14), 17051-17067, 1997.

Keller, J., Bojinski, S., and Prevot, A. S. H.: Simultaneous retrieval of aerosol and surface optical properties using data of the Multiangle Imaging SpectroRadiometer (MISR), Remote Sens. Environ., 107, 120-137, 2007.

Koepke, P.: Effective reflectance of the oceanic whitecaps, Appl. Optics, 23, 1816-1824, 1984.

Kokhanovsky, A. A., Breon, F.-M., Cacciari, A., Carboni, E.,
Diner, D., Di Nicolantonio, W., Grainger, R. G., Grey, W. M. F., Holler, R., Lee, K.-H., Li, Z., North, P. R. J., Sayer, A. M., Thomas, G. E., and von Hoyningen-Huene, W.: Aerosol remote sensing over land: a comparison of satellite retrievals using different algorithms and instruments, Atmos. Res., 85, 372-294, 2007.

Kokhanovsky, A. A.: Aerosol Optics, Springer-Praxis, Berlin, 2008.

Kokhanovsky, A. A. and de Leeuw, G. (Eds.): Satellite Aerosol Remote Sensing over Land, Springer-Praxis, Berlin, 2009.

Kokhanovsky, A. A., Cornet, C., Duan, M., Emde, C., Katsev, I. L., Labonnote, L.-C., Min Q., Nakajima T., Ota Y., Prikhach, A. P., Rozanov, V. V., Yokota, T., and Zege, E. P.: Benchmark results in vector radiative transfer, JQSRT, Journal of Quantitative Spectroscopy and Radiative Transfer, 111, 1931-1946, 2010

Lee, K. H., Li, Z., Kim, Y. J., and Kokhanovsky, A. A.: Atmospheric aerosol monitoring from satellite observations: a history of three decades, in Atmospheric and Biological Environmental Monitoring, edited by: Kim, Y. J., Platt, U., Gu, M. B., and Iwahashi, H., Springer, Berlin, 13-38, 2009.

Lenoble, J., Herman, M., Deuzé, J. L., Lafrance, B., Santer, R., and Tanré, D.: A successive order of scattering code for solving the vector equation of transfer in the Earth's atmosphere with aerosols, J. Quant Spectrosc. Ra., 107, 479-507, 2007.

Levenberg, K.: A method for the solution of certain non-linear problems in least-squares, Q. Appl. Math., 2, 164-168, 1944.

Levy, R. C., Remer, L., Mattoo, S., Vermote, E., and Kaufman, Y. J.: Second- generation algorithm for retrieving aerosol properties over land from MODIS spectral reflectance, J. Geophys. Res., 112, D13211, doi:10.1029/2006JD007811, 2007.

Levy, R. C.: The dark-land MODIS collection 5 aerosol retrieval: algorithm development and product evaluation, in: Satellite Aerosol Remote Sensing over Land, edited by: Kokhanovsky, A. A. and de Leeuw, G., Springer-Praxis, Berlin, 19-68, 2009.

Liu, L. and Mishchenko, M. I.: Toward unified satellite climatology of aerosol properties: Direct comparisons of advanced level 2 aerosol products, J. Quant Spectrosc. Ra., 109, 2376-2385, 2008.

Li, Z., Zhao, X., Kahn, R., Mishchenko, M., Remer, L., Lee, K.-H., Wang, M., Laszlo, I., Nakajima, T., and Maring, H.: Uncertainties in satellite remote sensing of aerosols and impact on monitoring its long-term trend: a review and perspective, Ann. Geophys., 27, 2755-2770, doi:10.5194/angeo-27-2755-2009, 2009.

Marquardt, D. R.: An algorithm for the least-squares estimation of nonlinear parameters, SIAM J. Appl. Math., 11, 431-441, 1963.

Martonchik, J. V., Diner, D. J., Kahn, R., Verstraete, M. M., Pinty, B., Gordon, H. R., and Ackerman, T. P.: Techniques for the retrieval of aerosol properties over land and ocean using multiangle data, IEEE T. Geosci. Remote, 36, 1212-1227, 1998.

Mishchenko, M. and Travis, L.: Satellite retrieval of aerosol properties over the ocean using polarization as well as intensity of reflected sunlight, J. Geophys. Res., 102(D14), 16989-17013, 1997.

Mishchenko, M. I., Cairns, B., Kopp, G., Schueler, C. F., Fafaul, B. A., Hansen, J. E., Hooker, R. J., Itchkawich, T., Maring, H. B., and Travis, L. D.: Precize and accurate monitoring of terrestrial aerosols and total solar irradiance: introducing the Glory mission, Bull. Am. Meteorol. Soc., 88, 677-691, 2007.

Mishchenko, M. I., Geogdzhayev, I. V., Liu, L., Lacis, A. A., 
Cairns, B., and Travis, L. D.: Toward unified satellite climatology of aerosol properties: What do fully compatible MODIS and MISR aerosol pixels tell us?, J. Quant. Spectrosc. Ra., 110, 402408, 2009

Nadal, F. and Bréon, F. M.: Parameterization of surface polarized reflectance derived from POLDER spaceborne measurements, IEEE T. Geosci. Remote, 37, 1709-1718, 1999.

NASA/ASDC: MISR Data and Information, http://eosweb.larc. nasa.gov/, 2002.

North, P. R. J.: Estimation of aerosol opacity and land surface bidirectional reflectance from ATSR-2 dual-angle imagery: operational method and validation, J. Geophys. Res., 107(D12), doi:10.1029/2000JD000207, 1-11, 2002.

North, P. R. J., Briggs, S. A., Plummer, S. E., and Settle, J. J.: Retrieval of land surface bidirectional reflectance and aerosol opacity from ATSR-2 multi-angle imagery, IEEE T. Geosci. Remote, 37(1), 526-537, 1999.

Ota, Y., Higurashi, A., Nakajima, T., and Yokota, T.: Matrix formulations of radiative transfer including the polarization effect in a coupled atmosphere-ocean system, Journal of Quantitative Spectroscopy and Radiative Transfer, 111, 878-894, 2010.

Remer, L. A., Kaufman, Y. J., Tanré, D., Mattoo, S., Chu, D. A., Martins, J. V., Li, R.-R., Ichoku, C., Levy, R. C., Kleidman, R. G., Eck, T. F., Vermote, E., and Holben, B. N.: The MODIS aerosol algorithm, products, and validation, J. Atmos. Sci., 62, 947-973, 2005

Rodgers, C. D.: Inverse Methods for Atmospheric Sounding: Theory and Practice, Series on Atmospheric, Oceanic and Planetary Physics, Vol. 2, World Scientific, Singapour, 2000.

Rozanov, A. A., Rozanov, V. V., Buchwitz, M., Kokhanovsky, A. A., Burrows, J. P.: SCIATRAN 2.0-a new radiative transfer model for geophysical applications in the $175-2400 \mathrm{~nm}$ spectral range, Adv. Space Res., 36, 1015-1019, 2005.

Rozanov, V. V. and Kokhanovsky, A. A.: The solution of the vector radiative transfer equation using the discrete ordinates technique: selected applications, Atmos. Res., 79, 241-265, 2006.

Schutgens, N. A. J., Tilstra, L. G., Stammes, P., and Bréon, F.-M.: On the relationship between Stokes parameters $Q$ and $U$ of atmospheric ultraviolet/visible/near-infrared radiation, J. Geophys. Res., 109, D09205, doi:10.1029/2003JD004081, 2004.

Sinuyk, A., Dubovik, O., Holben, B. N., Eck, T. F., Breon, F.M., Martonchik, J., Kahn, R., Diner, D. J., Vermote, E. F., Roger, J.-C., Lapyonok, T., and Slutser, I.: Simultaneous retrieval of aerosol and surface properties from a combination of AERONET and satellite data, Remote Sens. Environ., 107, doi:10.1016/j.rse.2006.07.02, 90-108, 2007.

Salomonson, V. V., Barnes, W. L., Maymon, P. W., Montgomery, H. E., and Ostrow, H.: MODIS, advanced facility instrument for studies of the Earth as a system, IEEE T. Goesci. Remote Sens., 27, 145-153, 1989.
Stamnes, K., Tsay, S.-C., Wiscombe, W., and Jayaweera, K.: Numerically stable algorithm for discrete-ordinate-method radiative transfer in multiple scattering and emitting later media, Appl. Optics, 27, 2502-2509, 1988.

Tanre, D., Kaufman, Y. J., Herman M., and Mattoo, S.: Remote sensing of aerosol properties over oceans using the MODIS/EOS spectral radiances, J. Geophys. Res., 102(D14), 16971-16988, 1997.

Thomas, G. E., Poulsen, C. A., Sayer, A. M., Marsh, S. H., Dean, S. M., Carboni, E., Siddans, R., Grainger, R. G., and Lawrence, B. N.: The GRAPE aerosol retrieval algorithm, Atmos. Meas. Tech., 2, 679-701, doi:10.5194/amt-2-679-2009, 2009.

Tynes, H., Kattawar, G. W., Zege, E. P., Katsev, I. L., Prikhach, A. S., and Chaikovskaya, L. I.: Monte Carlo and multicomponent approximation methods for vector radiative transfer by use of effective Mueller matrix calculations, Appl. Optics, 40, 400-412, 2001.

Vermote, E. F., Tanre, D., Deuze, J. L., Herman, M., Mocrette, J. J.: Second simulation of the satellite signal in the solar spectrum, 6S, an overview, IEEE T. Geosci. Remote, 35, 675-686, 1997.

Volten, H., Munoz, O., Rol, E., de Haan, J. F., Vassen, W., and Hovenier, J. W.: Scattering matrices of mineral aerosol particles at $441.6 \mathrm{~nm}$ and $632.8 \mathrm{~nm}$, J. Geophys. Res., 106(D15), 17375 17401, 2001.

von Hoyningen-Huene, W., Freitag, M., and Burrows, J. B.: Retrieval of aerosol optical thickness over land surfaces from top-of-atmosphere radiance, J. Geophys. Res., 108(D9), 4260, doi:10.1029/2001JD002018, 2003.

Wang, M. and Gordon, H. R.: Radiance reflected from the oceanatmosphere system : Synthesis from individual components of the aerosols size distribution, Appl. Optics, 33. 7088-7095, 1994.

Wanner, W., Strahler, A., Hu, B., Lewis, P., Muller, J., Li, X., Schaaf, C. B., and Barnsley, M.: Global retrieval of bidirectional reflectance and albedo over land from EOS MODIS and MISR data: Theory and algorithm, J. Geophys. Res., 102, 1714317161, 1997.

WCP-112: A Preliminary Cloudless Standard Atmosphere for Radiation Computation, World Meteorological Organization, Geneva, 1986.

Wiscombe, W.: Improved Mie scattering algorithms, Appl. Optics, 19, 1505-1509, 1980.

Yang, P. and Liou, K. N.: Geometric-optics-integral-equation method for light scattering by nonspherical ice crystals, Appl. Optics, 35, 6568-6584, 1996.

Zege, E. P., Katsev, I. L., and Polonsky, I. N.: Multicomponent approach to light propagation in clouds and mists, Appl. Optics, 32, 2803-2812, 1993.

Zege, E. P. and Chaikovskaya, L. I.: New approach to the polarized radiative transfer problem, J. Quant. Spectrosc. Ra., 55, 19-31, 1996. 